


\title{
Preventing Child Abuse and Neglect: A Technical Package for Policy, Norm, and Programmatic Activities
}

\author{
Developed by: \\ Beverly L. Fortson, $\mathrm{PhD}$ \\ Joanne Klevens, MD, PhD, MPH \\ Melissa T. Merrick, PhD \\ Leah K. Gilbert, MD, MSPH \\ Sandra P. Alexander, MEd
}

2016

Division of Violence Prevention

National Center for Injury Prevention and Control

Centers for Disease Control and Prevention

Atlanta, Georgia 


\title{
Centers for Disease Control and Prevention
}

Thomas R. Frieden, MD, MPH, Director

\section{National Center for Injury Prevention and Control \\ Debra E. Houry, MD, MPH, Director}

\author{
Division of Violence Prevention \\ James A. Mercy, PhD, Director
}

\section{Suggested citation:}

Fortson, B. L., Klevens, J., Merrick, M. T., Gilbert, L. K., \& Alexander, S. P. (2016). Preventing child abuse and neglect: A technical package for policy, norm, and programmatic activities. Atlanta, GA: National Center for Injury Prevention and Control, Centers for Disease Control and Prevention. 


\section{Contents}

Acknowledgements

External Reviewers 5

Strengthen Economic Supports for Families

Change Social Norms to Support Parents and Positive Parenting

Provide Quality Care and Education Early in Life 21

Enhance Parenting Skills to Promote Healthy Child Development 25

Intervene to Lessen Harms and Prevent Future Risk 29

Sector Involvement 33

Monitoring and Evaluation 35

Conclusion 36

References

Appendix 


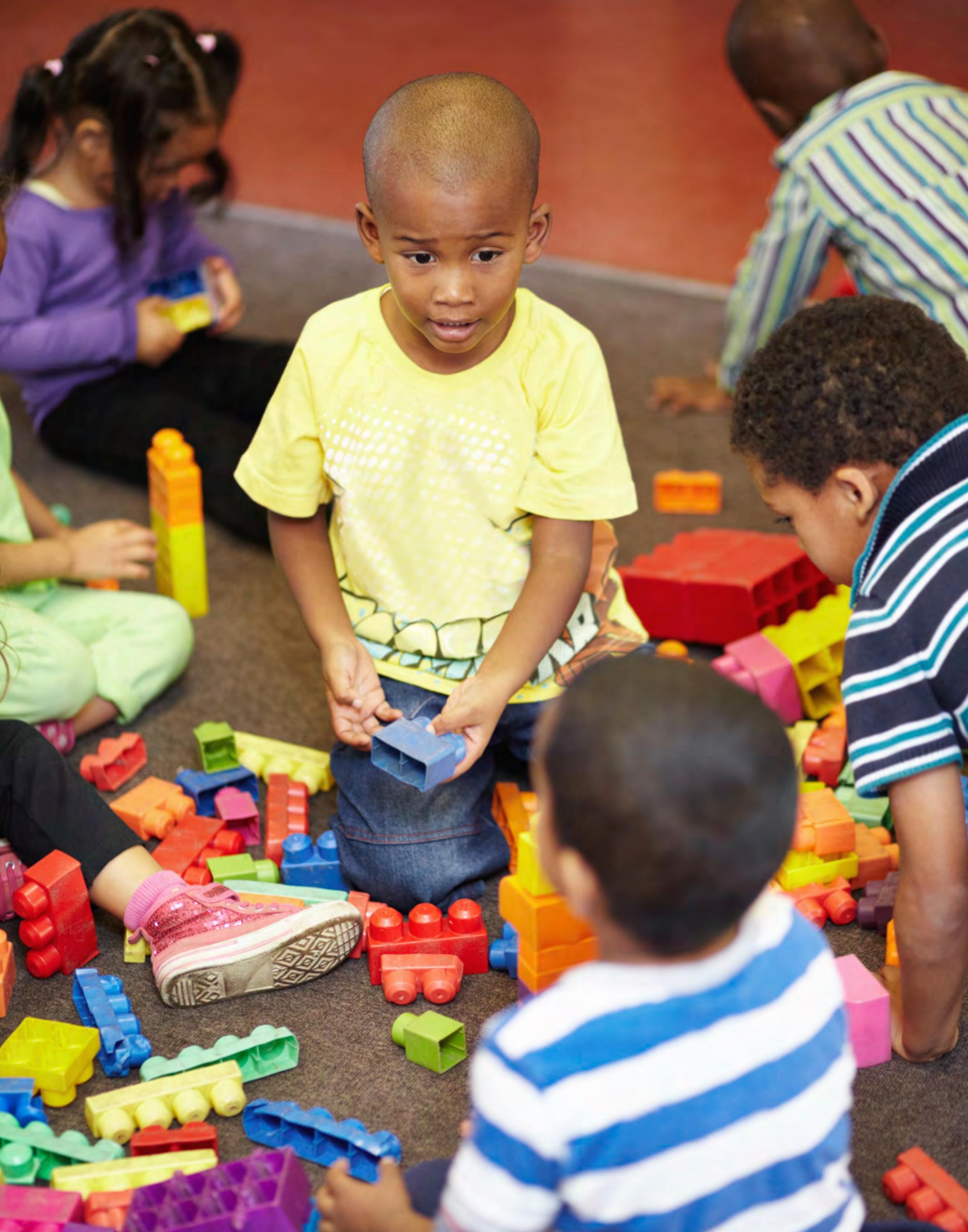




\section{Acknowledgements}

We would like to thank several individuals who contributed greatly to the development of this technical package. First, we give special thanks to Dr. Linda Dahlberg for her vision, guidance, and support throughout the development of this package. We thank Division, Center, and CDC leadership, and members of the CDC Division of Violence Prevention Child Maltreatment Workgroup for their careful review and helpful feedback on earlier iterations of this document. We thank Alida Knuth for her formatting and design expertise. We also extend our thanks and gratitude to all of the external reviewers for their helpful feedback, support and encouragement for this document.

\section{External Reviewers}

Marissa Abbott

California Department of Health

Melissa Brodowski

Administration for Children and Families

Lauren Fischman

Administration for Children and Families

Marilyn Gisser

Washington State Department of Health

Monique Fountain Hanna

Health Resources and Services Administration

\section{Cailin O'Connor}

Center for the Study of Social Policy

Diane Pilkey

Health Resources and Services Administration
Janet Rosenzweig

Prevent Child Abuse America

Elaine Stedt

Administration for Children and Families

Kiersten Stewart

Futures Without Violence

Calondra Tibbs

National Association of City and County Health Officials

Julia Wei

California Department of Health

Steve Wirtz

California Department of Health

Mao Yang

Administration for Children and Families 


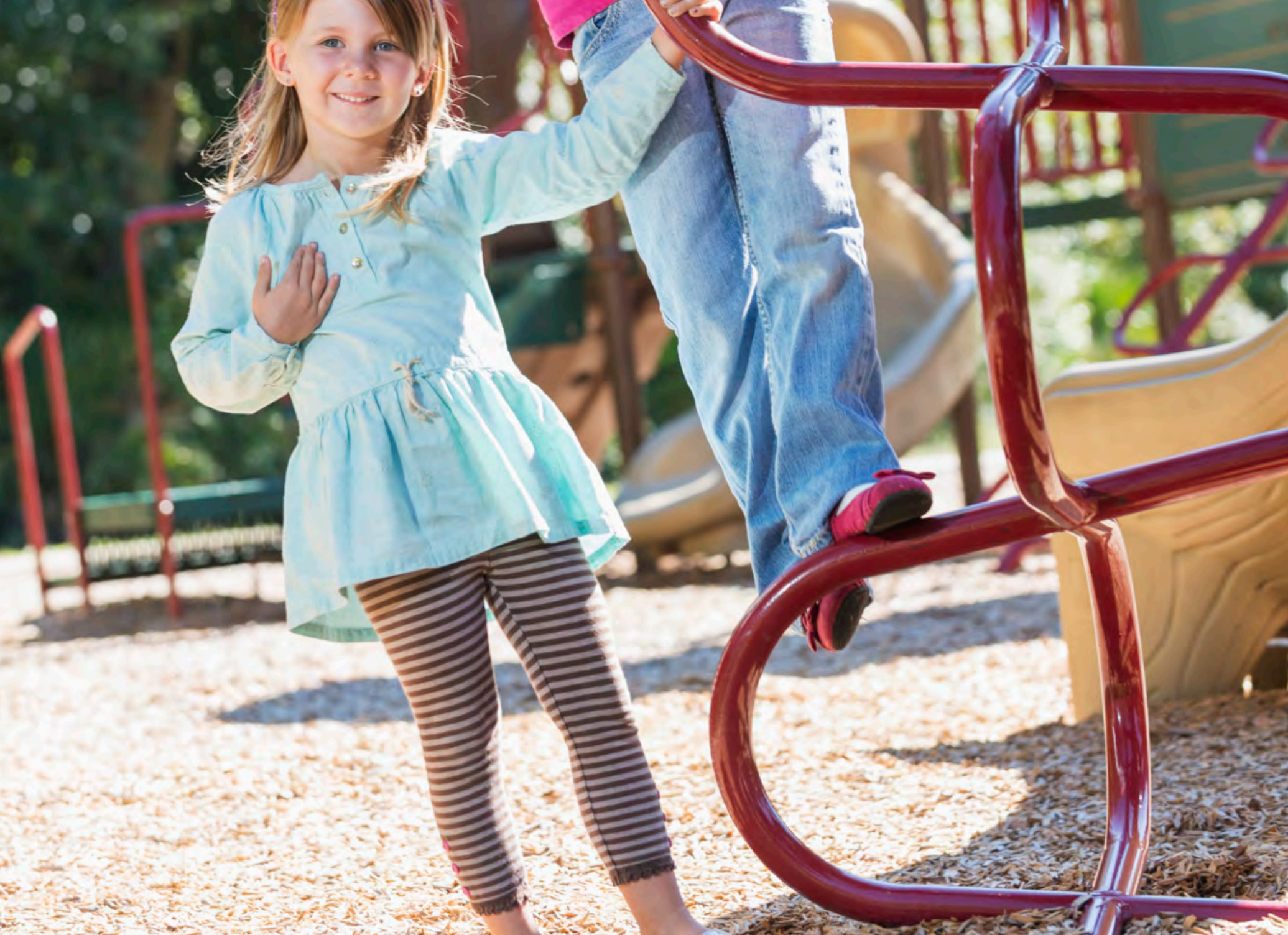




\section{Overview}

This technical package represents a select group of strategies based on the best available evidence to help prevent child abuse and neglect. These strategies include strengthening economic supports to families; changing social norms to support parents and positive parenting; providing quality care and education early in life; enhancing parenting skills to promote healthy child development; and intervening to lessen harms and prevent future risk. The strategies represented in this package include those with a focus on preventing child abuse and neglect from happening in the first place as well as approaches to lessen the immediate and long-term harms of child abuse and neglect. These strategies range from a focus on individuals, families, and relationships to broader community and societal change. This range of strategies is needed to better address the interplay between individual-family behavior and broader neighborhood, community, and cultural contexts. ${ }^{1}$

This package supports CDC's Essentials for Childhood framework for preventing child abuse and neglect. In particular, it articulates a select set of strategies and specific approaches that can create the context for healthy children and families and prevent child abuse and neglect (Goals 3 and 4 of the framework—see below).

Commitment, cooperation, and leadership from numerous sectors, including public health, education, justice, health care, social services, business/labor, and government can bring about successful implementation of this package.

\section{What is a Technical Package?}

A technical package is a compilation of a core set of strategies to achieve and sustain substantial reductions in a specific risk factor or outcome. ${ }^{2}$ Technical packages help communities and states prioritize prevention activities based on the best available evidence. This technical package has three components. The first component is the strategy or the preventive direction or actions to achieve the goal of preventing child abuse and neglect. The second component is the approach. The approach includes the specific ways to advance the strategy. This can be accomplished through programs, policies, and practices. The evidence for each of the approaches in preventing child abuse and neglect or its associated risk factors is included as the third component. This package is intended as a resource to guide and inform prevention decision-making in communities and states.

\section{Essentials for Childhood: Steps to Create Safe, Stable, Nurturing Relationships and Environments}

The Essentials for Childhood framework proposes steps communities can consider to promote the types of relationships and environments that help children grow up to be healthy and productive citizens. The framework is organized around four goals and related steps to promote safe, stable, nurturing relationships and environments for children and families.

\section{Four goal areas:}

1) raise awareness and commitment;

2) use data to inform actions;

3) create the context for healthy children and families through norms change and programs;

4) create the context for healthy children and families through policies.

www.cdc.gov/violenceprevention/pdf/essentials for childhood framework.pdf 


\section{Preventing Child Abuse and Neglect is a Priority}

Child maltreatment includes all types of abuse and neglect of a child under the age of 18 by a parent, caregiver, or another person in a custodial role (e.g., clergy, coach, teacher) that results in harm, potential for harm, or threat of harm to a child. ${ }^{3}$ There are four common types of child maltreatment: ${ }^{3}$

- Physical abuse is the use of physical force, such as hitting, kicking, shaking, burning, or other shows of force against a child.

- Sexual abuse involves inducing or coercing a child to engage in sexual acts. It includes behaviors such as fondling, penetration, and exposing a child to other sexual activities.

- Emotional abuse refers to behaviors that harm a child's self-worth or emotional well-being. Examples include name calling, shaming, rejection, withholding love, and threatening.

- Neglect is the failure to meet a child's basic physical and emotional needs. These needs include housing, food, clothing, education, and access to medical care.

Child abuse and neglect is highly prevalent. Self-report data suggest that at least 1 in 7 children have experienced child abuse and/or neglect in the last year. ${ }^{4}$ Not all children, however, experience abuse and neglect at the same rates. Younger children are more likely to experience fatal abuse and neglect, ${ }^{5}$ while 14 - to 17-year-olds are more likely to experience non-fatal abuse and neglect. ${ }^{4}$ Race and ethnicity and family income are also factors that may affect a child's exposure. Child protective services data show high rates of victimization among African-American children. African-American children experience abuse and neglect at rates that are nearly double those for white children. These differences are generally attributed to various community and societal factors, including poverty as well as differences in reporting and investigation. ${ }^{5}$ Children living in families with a low socioeconomic status (SES) ${ }^{*}$ have rates of child abuse and neglect that are five times higher than those of children living in families with a higher SES. ${ }^{6}$ Irrespective of data source, definitions, and measures, the true magnitude of child abuse and neglect is likely underestimated, and children of all ages, races, and ethnicities deserve safe, stable, nurturing relationships and environments to achieve maximal health and life potential.

Child abuse and neglect is associated with several risk factors. Risk for child abuse and neglect perpetration and victimization is influenced by a number of individual, family, and environmental factors, all of which interact to increase or decrease risk over time and within specific contexts. Risk factors for victimization include child age and special needs that may increase caregiver burden (e.g., developmental and intellectual disabilities, mental health issues, and chronic physical illnesses). ${ }^{7}$ Risk factors for perpetration include young parental age, single parenthood, large number of dependent children, low parental income, parental substance abuse, parental mental health issues, parental history of abuse or neglect, social isolation, family disorganization, parenting stress, intimate partner violence, poor parent-child relationships, community violence, and concentrated neighborhood disadvantage (e.g., high poverty and residential instability, high unemployment rates). ${ }^{7}$ Although risk factors provide information about who is most at risk for being a victim or a perpetrator of child abuse and neglect, they are not direct causes and cannot predict who will be a victim or a perpetrator.

Factors that protect or buffer children from being abused or neglected are known as protective factors. Supportive family environments and social networks consistently emerge as protective factors; ${ }^{7,8}$ however, other factors such as parental employment, adequate housing, and access to health care and social services may also serve to protect against child abuse and neglect. Unfortunately, no single factor tells the entire story about how and why child abuse and neglect occurs, and the risk and protective factors differ depending on the type of child abuse and neglect being studied. For additional information on risk and protective factors for child abuse and neglect, see Merrick, Fortson, and Mercy ${ }^{9}$ and Fortson and Mercy. ${ }^{10}$

* Defined as having a household income below $\$ 15,000$ a year; parents' highest education level less than high school; or any member of the household a participant in a poverty program (e.g., TANF, food stamps, public housing, energy assistance, or subsidized school meals). ${ }^{6}$ 
The health and economic consequences of child abuse and neglect are substantial. Child abuse and neglect is associated with negative human, societal, and economic impacts. Children who are abused and neglected may suffer immediate physical injuries (e.g., cuts, bruises, burns, broken bones), as well as emotional and psychological problems (e.g., posttraumatic stress, anxiety). ${ }^{11}$ Child abuse and neglect can also affect broader health outcomes, mental health, social development, and risk-taking behavior into adolescence and adulthood. Strong evidence confirms that childhood violence increases the risks of injury, sexually transmitted infections, including HIV, mental health problems, delayed cognitive development, reproductive health problems, involvement in sex trafficking, and noncommunicable diseases, which, in turn, can cause damage to the nervous, endocrine, circulatory, musculo-skeletal, reproductive, respiratory, and immune systems. ${ }^{11,12}$ Given the high prevalence of child abuse and neglect and its vast consequences, the associated economic impact is substantial. In the United States, the total lifetime economic burden associated with child abuse and neglect was approximately $\$ 124$ billion in $2008 .{ }^{13}$

Child abuse and neglect is preventable. Much progress has been made in understanding how to prevent child abuse and neglect. Child abuse and neglect is the result of the interaction of a number of individual, family, and environmental factors. ${ }^{14}$ Consequently, there is strong reason to believe that the prevention of child abuse and neglect requires a comprehensive focus that crosscuts key sectors of society (e.g., public health, government, education, social services, and justice). ${ }^{15}$ In addition, there is an important need to increase the capacity of state and local governments to implement and scale up effective interventions that can reduce child abuse and neglect. ${ }^{16,17}$

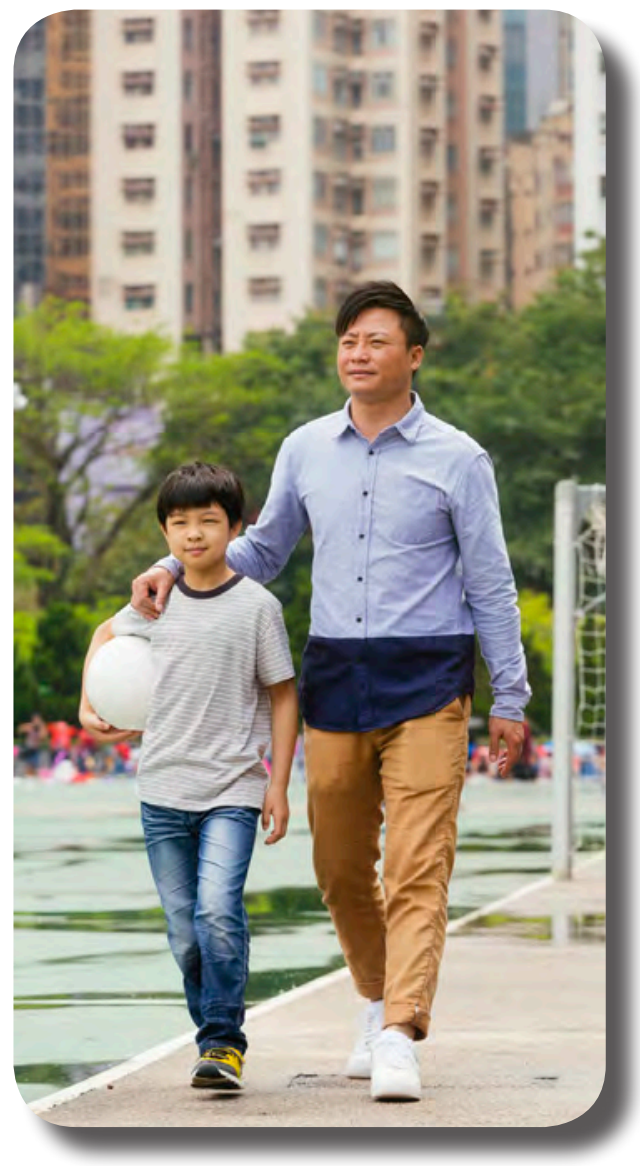

Preventing child abuse and neglect can also prevent other forms of violence. Each of the various forms of violence are interrelated and share many risk and protective factors, ${ }^{18}$ consequences, ${ }^{19,20}$ and effective approaches to prevention. ${ }^{21}$ Given the overlap of the risk and protective factors for child abuse and neglect and other forms of violence, it stands to reason that the primary prevention of child abuse and neglect can prevent other forms of violence and abuse. 18,22 Moreover, strategies that support the development of safe, stable, and nurturing relationships between parents or caregivers and their children could be key in preventing the early development of violent behavior in children. ${ }^{23-25}$ Emerging evidence suggests that by stemming the early development of violent behavior, such relationships can also reduce many types of violence occurring in adolescence and early adulthood, such as youth violence, intimate partner and dating violence, sexual violence, and self-directed violence. ${ }^{26}$

\section{Assessing the Evidence}

This technical package includes programs, practices, and policies with evidence of impact on child abuse and neglect victimization, perpetration, or risk factors for child abuse and neglect. To be considered for inclusion in the technical package, the program or policy selected had to meet at least one of these criteria: a) meta-analyses or systematic reviews showing impact on child abuse and neglect victimization or perpetration; b) evidence from at least one or more rigorous (e.g., randomized controlled trial $[\mathrm{RCT}]$ or quasi-experimental design) evaluation study that found significant preventive effects on child abuse and neglect victimization or perpetration; c) meta-analyses or systematic reviews showing impact on risk factors for child abuse and neglect victimization or perpetration; or d) evidence from at least one rigorous (e.g., RCT or quasi-experimental design) evaluation study that found significant impacts on risk factors for child abuse and neglect victimization or perpetration. Finally, consideration was given to the likelihood of achieving beneficial effects on multiple forms of violence; no evidence of harmful effects on specific outcomes or with particular subgroups; and feasibility of implementation in a U.S. context if the program, policy, or practice was evaluated in another country. 


\section{$\infty$}

Within this technical package, some approaches do not yet have research evidence demonstrating impact on rates of child abuse and neglect victimization or perpetration but instead are supported by evidence indicating impacts on risk factors for child abuse and neglect (e.g., parenting stress, parental mental health). In terms of the strength of the evidence, programs that have demonstrated effects on child abuse and neglect outcomes provide a higher level of evidence, but the evidence base is not that strong in all areas. For instance, there has been less evaluation of the effects of community and societal level approaches in preventing child abuse and neglect. Thus, approaches in this package that have effects on risk factors reflect the developmental nature of the evidence base and the use of the best available evidence at a given time.

It is also important to note that there is often significant heterogeneity among the programs, policies, or practices that fall within one approach in terms of the nature and quality of the available evidence. Not all programs, policies, or practices that utilize the same approach (e.g., home visitation) are equally effective, and even those that are effective may not work across all populations. Very few evaluation studies have assessed outcomes across diverse populations (e.g., racial/ethnic; populations with disabilities). Moreover, not all programs were designed for use with diverse populations; thus, tailoring of programs and more evaluation may be necessary to address different population groups. The examples provided, while not intended to be a comprehensive list of evidence-based programs, policies, or practices, illustrate models that have been shown to impact rates of child abuse or neglect or have empirical support demonstrating impact on risk factors for child abuse or neglect. In practice, the effectiveness of the programs, policies and practices identified in this package will be strongly dependent on the quality of their implementation. Implementation guidance to assist practitioners, organizations and communities will be developed separately.

\section{Contextual and Cross-Cutting Themes}

The strategies and approaches that have been included in this technical package represent different levels of the social ecology, with efforts intended to impact the community and societal levels, as well as individual and relationship levels. The strategies and approaches are intended to work in combination and reinforce each other to prevent child abuse and neglect (see box below). The strategies are arranged in order such that those strategies hypothesized to have the greatest potential for broad public health impact on child abuse and neglect are included first, followed by those that might impact more select populations (e.g., first-time parents or those for whom child abuse and neglect is already present).

\section{Preventing Child Abuse and Neglect}

\section{Strategy}

\section{Strengthen economic} supports to families

Change social norms to support parents and positive parenting

Provide quality care and education early in life

Enhance parenting skills to promote healthy child development

Intervene to lessen harms and prevent future risk

\section{Approach}

- Strengthening houshold financial security

- Family-friendly work policies

Public engagement and education campaigns

Legislative approaches to reduce corporal punishment

- Preschool enrichment with family engagement

- Improved quality of child care through licensing and accreditation

- Early childhood home visitation

Parenting skill and family relationship approaches

Enhanced primary care

Behavioral parent training programs

- Treatment to lessen harms of abuse and neglect exposure

- Treatment to prevent problem behavior and later involvement in violence 



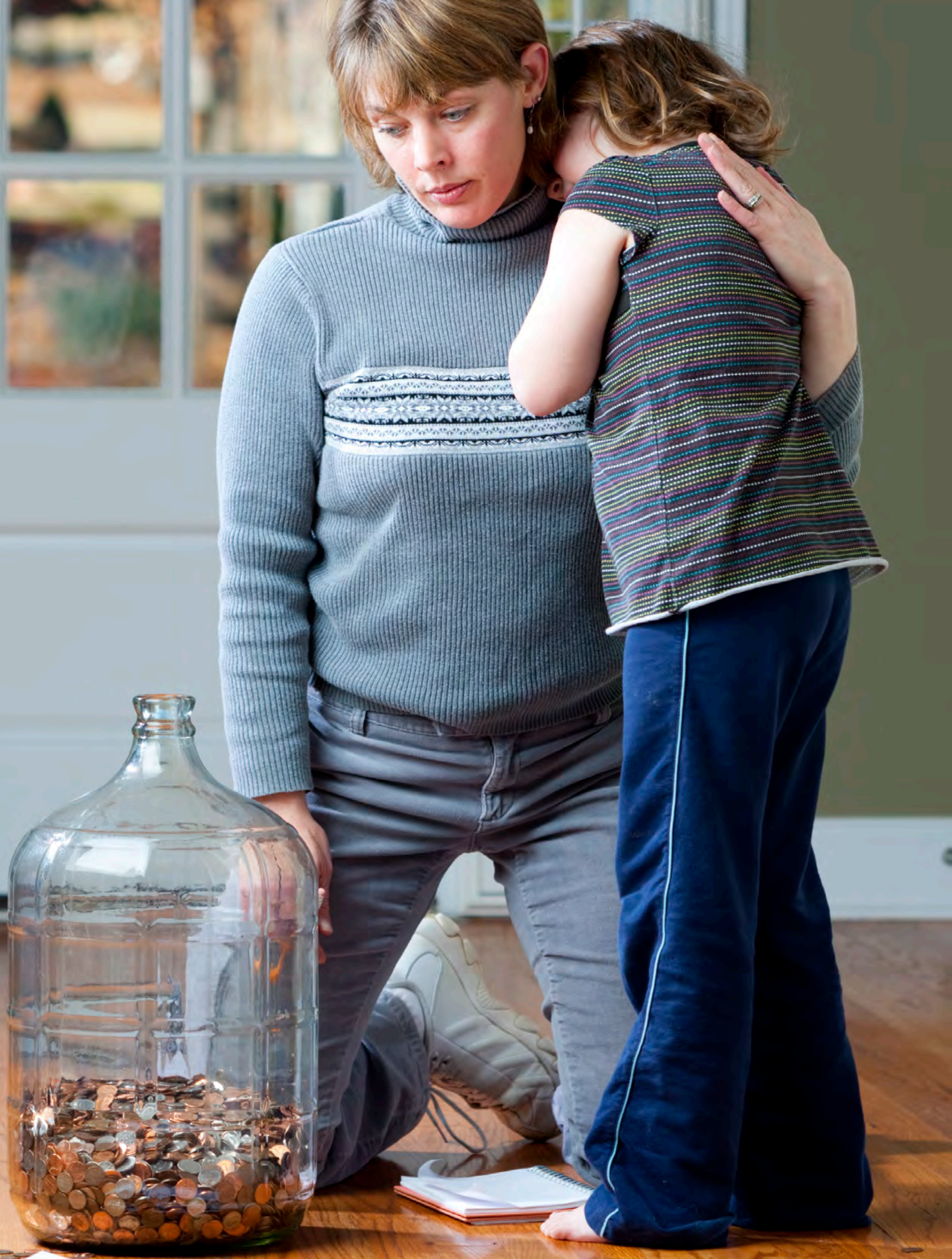




\section{Strengthen Economic Supports for Families}

\section{Rationale}

Policies that improve the socioeconomic conditions of families tend to have the largest impacts on health. ${ }^{34}$ Strong empirical evidence consistently links low income to children's development, academic achievement, and health, 35,36 including exposure to child abuse and neglect. ${ }^{37}$ Policies that strengthen household financial security can reduce child abuse and neglect by improving parents' ability to satisfy children's basic needs (e.g., food, shelter, medical care), provide developmentally appropriate child care, and improve parental mental health.

Policies can change the context for families by improving the balance between work and family ("family-friendly work"), thereby allowing parents to provide the necessary care for children and increasing the likelihood that children experience safe, stable, nurturing relationships and environments. Studies show several "family-friendly" work policies reduce risk factors for child abuse and neglect, such as stress and depression.

\section{Approaches}

Economic supports for families can be strengthened by targeting household financial security and family-friendly work.

Strengthening household financial security can reduce child abuse and neglect by improving parents' ability to satisfy children's basic needs (e.g., food, shelter, medical care), provide developmentally appropriate child care, and reduce parental stress and depression, both risk factors for child abuse and neglect. ${ }^{37}$ Strengthening household financial security may also reduce children's exposure to crowding and contribute to residential stability and stability in child care arrangements. Household financial security can be strengthened in various ways:

- Child support payments: States can modify how Temporary Assistance for Needy Families (TANF) benefits are affected by child support payments. In many states, the child support payments are used by the state to reimburse itself, but states may also elect to allow some or all of the child support payment to be passed on to the custodial parent and child without any reduction in the TANF benefits. Allowing child support payments to be passed on to the custodial parent in part or in full without reducing TANF benefits increases household income.

- Tax credits for families with children (e.g., state and federal Earned Income Tax Credit, EITC) help low income families increase their income while incentivizing work or offsetting the costs of child-rearing. The federal EITC is a refundable credit originally designed to encourage work by offsetting the impact of federal taxes on lowincome families. The amount of the credit varies depending on income earned through work, marital status, and the number of qualifying children. State EITC's are usually based on a percentage of the federal EITC and vary in their eligibility and funding amounts; approximately half of the states in the U.S. have enacted EITCs. ${ }^{38}$

- State options for managing federal nutrition assistance programs: The Supplemental Nutrition Assistance Program (SNAP) is a federally funded program managed by the U.S. Department of Agriculture (USDA) that provides cash benefits, which can only be used to purchase food, to low income households. States have several options that can facilitate access to SNAP (e.g., online application; frequency or simplicity with which households report household income or work hours; whether child support is considered in income calculations; disqualifications imposed). ${ }^{39}$ SNAP benefits help low income parents meet children's basic needs for food. Because SNAP benefits allow a parent's income from other sources to be used on things besides food, SNAP decreases family poverty and poverty among children. ${ }^{40}$ SNAP also reduces the severity of food insecurity. ${ }^{41}$ 
- Assisted housing mobility: States can choose to use the U.S. Housing and Urban Development's Community Development Block Grant (CDBG) money to purchase properties in low poverty neighborhoods and lease them to low income families at lower rent. ${ }^{42}$ Alternatively, states can use Section 8 Housing Choice Voucher funds and condition their use to rentals in low poverty neighborhoods, while at the same time coupling them with measures that prevent discriminating against Section 8 voucher holders. ${ }^{42}$ Assisted housing mobility through these programs enables families from high poverty neighborhoods to relocate to more stable, better resourced, and safer communities while saving on rent. These savings can be used for other necessities.

- Subsidized child care provides vouchers, lower cost child care, or cash transfers to low-income families to off-set the cost of quality, full-time child care. Subsidized child care improves low income families' economic well-being by reducing child-care costs; many parents receiving subsidies report that the subsidies enhance their financial well-being. ${ }^{43}$ States can elect to raise income threshold limits to expand eligibility and consider household expenses when calculating eligibility; expand the definition of approved activities to include training, education, job search time, rest hours (for parents working second or third shifts), and temporary leave; increase the amount of the subsidy, provide increases based on the quality of care provided, and improve monitoring of quality; have graduated phase-out periods that would allow clients to slowly earn their way off the program rather than face a blunt income threshold; simplify the application process and shorten wait times for subsidy approval; simplify the verification process, the reapplication process, and reduce the frequency of recertification to improve continuity of child care; and increase the number of providers with non-standard hours (e.g., evenings, weekends) or incentivize providers to provide extended hours.

Family-friendly work policies change the context for families by improving the balance between work and family while ensuring economic security. This makes it easier for parents to provide necessary care for children.

- Livable wages allow working parents enough income to cover the costs of living and provide for their children's basic needs (e.g., food, shelter, appropriate child and medical care), reducing the likelihood of child neglect. Its impacts on parental mental health may also improve parenting behaviors.

- Paid leave provides income replacement to workers on leave for family caregiving, bonding with a new child (paid parental leave), or personal leave taken to recover from a serious health condition (paid sick leave) or get rested and re-energized (paid vacation). Paid leave can reduce risk factors for child abuse and neglect (e.g., parental stress).

- Flexible and consistent schedules provide workers with a predictable pattern of work and/or allow for adaptability within the work environment. Flexible schedules include flexibility in work scheduling (e.g., compressed work weeks, flexible beginning/ending times to work day, flexibility in scheduling shifts and breaks to allow for child care coverage), flexibility in the number of hours worked (e.g., part-time work), and flexibility in the workplace location (e.g., home office, satellite location, alternate location). Inconsistent schedules or shiftwork can make it challenging to balance work and family responsibilities, which includes obtaining stable child care and access to child care assistance. ${ }^{44}$

\section{Potential Outcomes}

- Improvements in children's health, development, and health insurance coverage

- Reductions in physical abuse of children

- Reductions in child neglect

- Reductions in unintentional or undetermined causes of childhood injury

- Reductions in maternal depression and parental stress

- Reductions in adolescent risky health behaviors

- Reductions in chronic disease among adults and leading causes of death 

A study based on variations between provinces and survey data showed child tax credits of \$769 (2004 Canadian dollars) were associated with reductions in grade repetition, children's hyperactivity-inattention, conduct disorder-physical aggression, and emotional disorder/anxiety scores, as well as reductions in maternal depression in the overall sample. No impacts were noted on children's math or vocabulary test scores or probability of being diagnosed with a learning disability or prosocial behavior. ${ }^{56}$ Several of the factors for which the child tax credit showed impacts (e.g., maternal depression, children's hyperactivity, conduct disorder) are risk factors for child physical abuse and neglect, ${ }^{37}$ and impacts on these factors may prevent abuse and neglect long-term.

- State options for managing federal nutrition assistance programs: Food insecurity is a risk factor for child abuse and neglect. ${ }^{57}$ SNAP reduces the severity of food insecurity ${ }_{1}{ }^{41}$ but does not change the probability of families being food insecure. A study linking administrative databases found that among children enrolled in Medicaid, families receiving SNAP or receiving nutrition benefits through the Special Supplemental Nutrition Program for Women, Infants, and Children (WIC) had fewer reports of abuse and neglect than families not receiving SNAP or WIC. ${ }^{58}$

- Assisted housing mobility: Housing rental assistance that facilitates moving to better resourced low poverty communities reduces household victimization, neighborhood social disorder, and increases neighborhood safety. ${ }^{59}$ Evidence from the Moving to Opportunity (MTO) experiment found a number of positive outcomes. ${ }^{60-62}$ The MTO experiment was a large randomized controlled trial conducted in Baltimore, Boston, Chicago, Los Angeles and New York in which low-income families living in high-poverty neighborhoods were randomly assigned to one of three groups: a group offered a housing voucher that could only be used to move to a low-poverty neighborhood (i.e., census tracts with 1990 poverty rates below 10 percent) along with housingmobility counseling; a group offered a Section 8 housing voucher without any location restriction; and a control group. Participants were originally enrolled in the trial starting in 1994 and then followed for 10-15 years. MTO participants relative to controls experienced less psychological distress and depression, ${ }^{61,62}$ which are risk factors for child abuse and neglect. ${ }^{37}$ Children who moved to the lower poverty neighborhoods before age thirteen were more likely to attend college and went on to earn $31 \%$ more than those who did not receive the conditional voucher. ${ }^{63}$ Moreover, the girls raised in lower poverty neighborhoods were more likely to marry, and when they had children, more likely to maintain a relationship with the father. The girls were also more likely to live in lower poverty neighborhoods as adults. Thus, the grandchildren of the intervention group were more likely to be raised by two parents, enjoy higher family incomes and spend their entire childhood in neighborhoods with lower poverty, potentially breaking the cycle of poverty. Other studies have found that housing assistance also reduces homelessness, ${ }^{64}$ a risk factor for placements with relatives or in foster care. ${ }^{65}$

- Subsidized child care: Parents receiving child care subsidies tend to choose better quality child care. ${ }^{66}$ Better quality child care increases the likelihood that children will experience safe, stable, nurturing relationships and environments and decreases the risk of maltreatment-related fatalities. ${ }^{67}$ In multi-level regression analyses of within-state trends, states meeting demand for child care assistance (i.e., no wait lists) decreased rates of child abuse and neglect after controlling for states' childhood poverty, adults without a high school diploma, unemployment, child burden, and racial and ethnic composition; ${ }^{68}$ neighborhoods with more licensed child care spaces relative to child care need, as defined by the number of 0 - to 5-year-olds in the neighborhood with working parents, had lower rates of child abuse and neglect. ${ }^{69}$ Access to affordable child care also reduces parental stress, ${ }^{70}$ and having access to high-quality child care is associated with fewer symptoms of maternal depression. ${ }^{71}$ Both parental stress and maternal depression are risk factors for child abuse and neglect. ${ }^{37}$ Moreover, children who live with unrelated adults are nearly 50 times more likely to die of inflicted injuries than children who live with both biological parents, ${ }^{67}$ thereby highlighting the importance of quality child care, as mothers would not have to leave the child alone with other (unrelated) adults in the home. 


\section{Family-friendly work policies}

- Livable wages: A matched controlled trial of a guaranteed annual livable income resulted in decreases in two of the risk factors for child abuse and neglect perpetration: low levels of education and mental health problems. ${ }^{72}$ Specifically, livable income was associated with improved school performance and graduation rates among children; a reduction in hospitalization rates, particularly for injuries; and physician visits, especially for mental health. ${ }^{72}$

- Paid leave: Paid maternity leave increases the frequency and duration of breastfeeding. ${ }^{73}$ Breastfeeding, in turn, is potentially protective against child abuse and neglect. In a 15-year cohort study comparing three groups of children (i.e., non-breastfed children, children breastfed for fewer than four months, and children breastfed for four or more months), the non-breastfed children had a 3.8 times greater risk of experiencing child abuse and neglect by their mothers relative to those breastfed for four or more months. ${ }^{74}$ Children breastfed for fewer than four months had a 2.6 times greater risk than those breastfed for four or more months. In addition, mothers who are employed prior to child birth and who delay returning to work after giving birth experience fewer depressive symptoms than those who return to work earlier. ${ }^{75}$ This may have an impact on child abuse and neglect, as depression is a risk factor for child abuse and neglect. ${ }^{37}$ Paid family leave is also significantly associated with reductions in hospitalizations for abusive head trauma. ${ }^{76}$ Paid sick days and paid vacation are associated with lower rates of depression and stress, ${ }^{77}$ both of which are risk factors for child physical abuse and neglect. ${ }^{37}$

- Flexible and consistent schedules: When the daily timing of work schedules is irregular and unpredictable, parents often have difficulty securing consistent, quality child care. ${ }^{78}$ Children whose parents work unpredictable schedules have more cognitive deficits (e.g., memory, learning, problem solving) than children whose parents have more predictable schedules. ${ }^{78-80}$ Moreover, parents who work irregular shift times, in contrast with those with more standard, regular shift times, experience greater work-family conflict ${ }^{81}$ and are more likely to be stressed, ${ }^{78}$ which is a risk factor for child physical abuse and neglect. ${ }^{37}$ Flexible and consistent schedules (i.e., work-life fit), on the other hand, are associated with lower rates of depression and stress, ${ }^{77}$ both of which are risk factors for child physical abuse and neglect. ${ }^{37}$

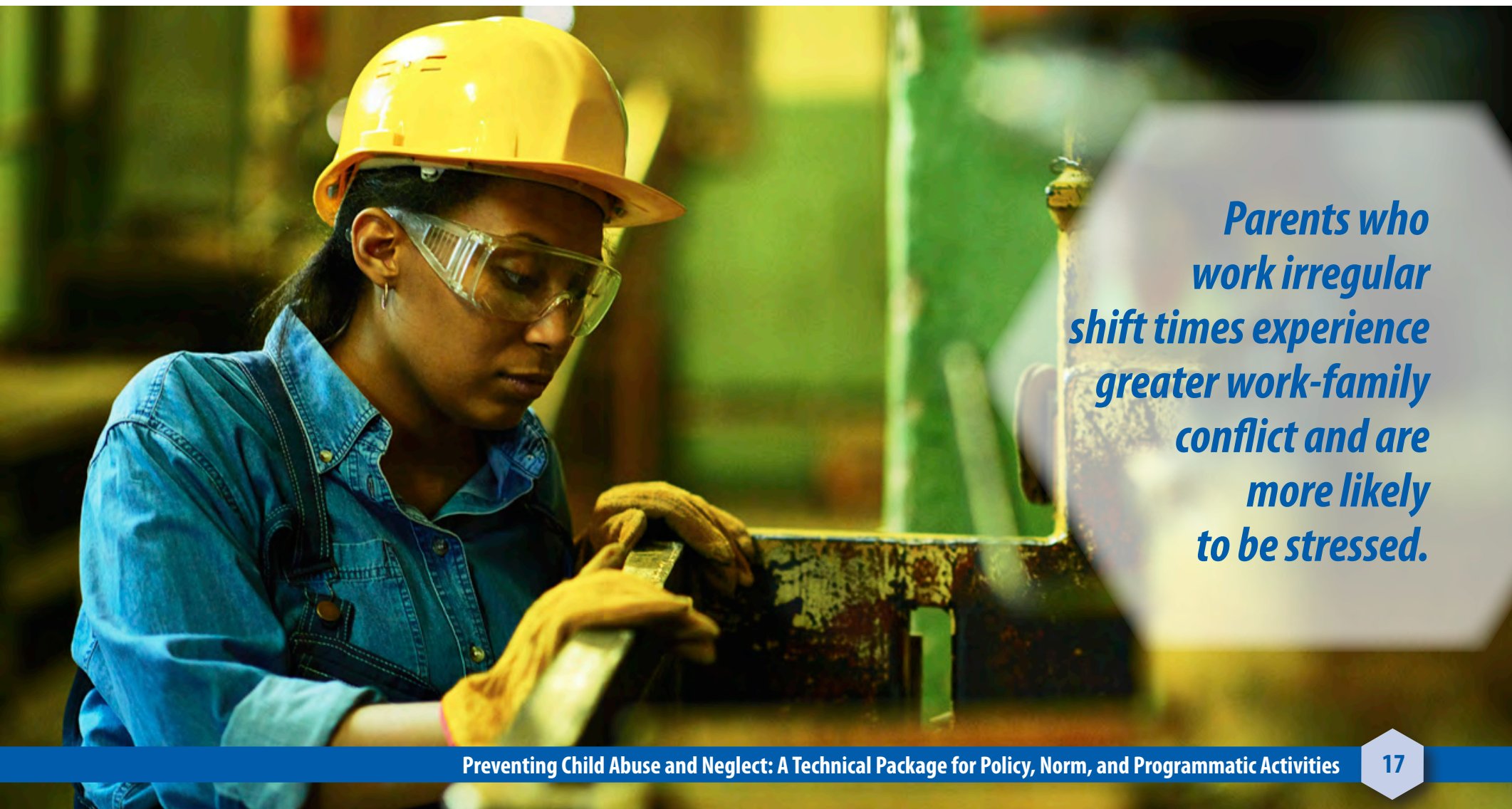




\section{$\infty$}

\section{Change Social Norms to Support Parents and Positive Parenting}

\section{Rationale}

Changing social norms that accept or allow indifference to violence is very important to the prevention of child abuse and neglect. Social norms are group-level beliefs and expectations about how members of the group behave or should behave. ${ }^{82}$ The group can be large or small, ranging from the cultural norms of an entire country to those of a small sub-population. There are a number of norms that relate to child development and child safety, including norms for safe sleep, breastfeeding, child passenger safety, talking to young children, and shared responsibility for children. One social norm that is particularly relevant to preventing child abuse and neglect relates to how parents discipline their children. Another has to do with whether it is appropriate for parents to seek help in parenting.

In addition to changing social norms related to behaviors, changing the way we think and talk about why child abuse and neglect occurs and who is responsible for preventing it (our narrative) are important in informing policy choice and change..$^{83}$ For example, a dominant narrative in the United States is the idea that anyone can get ahead on their own if they work hard enough. This focus on individual responsibility ignores contextual causes and societal solutions to complex problems such as child abuse and neglect.

\section{Approaches}

Two types of approaches seek to change social norms and the way we think and talk about child abuse and neglect. These include public engagement and education campaigns and legislative approaches to reduce corporal punishment.

Public engagement and education campaigns use communication strategies (e.g., framing and messaging or social marketing), a range of communication channels (e.g., mass or social media) and community-based efforts (e.g., town hall meetings, neighborhood screenings and discussions) to reframe the way people think and talk about child abuse and neglect and who is responsible for preventing it. Effective frames highlight a problem and point the audience toward solutions. ${ }^{84}$

Legislative approaches to reduce corporal punishment can help establish norms around safe, more effective discipline strategies to reduce the harms of harsh physical punishment, particularly if paired with engagement and education campaigns. No state currently limits the use of corporal punishment in the home, but some states have banned its use in alternative care settings (foster care or institutional care), child day care and after school care, schools, and juvenile detention facilities. ${ }^{85}$

\section{Potential Outcomes}

- Shift in perceived responsibility for children - from personal to shared responsibility

- Increase in public support for policies supportive of children and families

- Reduction in beliefs that corporal punishment of children is appropriate

- Reduction in reported use of corporal punishment

- Increase in beliefs that nurturing children at every age is appropriate

- $\quad$ Reduction in beliefs that getting help for parenting is bad

- Increase in seeking help for parenting

- Increase in public awareness of factors that can inhibit or promote healthy child development 


\section{Evidence}

There is evidence suggesting that public engagement and education campaigns and legislative approaches to reduce corporal punishment can impact behaviors related to child abuse and neglect.

Public engagement and education campaigns. Public engagement and education campaigns using social marketing techniques have been used effectively in public health to change behaviors, ${ }^{86}$ and specifically, for behaviors related to child abuse and neglect. ${ }^{87}$ For example, the Breaking the Cycle campaign, which promoted the benefits of not abusing children and helping parents understand the cycle of abuse (i.e., children learn from their parents), was effective in changing parents' emotional abuse of their children and children's exposure to parental conflict. ${ }^{88} \mathrm{~A}$ postcampaign survey showed that up to $44 \%$ of parents had contemplated changing their behavior and up to $16 \%$ had tried to stop yelling at, swearing at or putting their child down and fighting or arguing in front of their children. A pre- and post- comparison of another campaign focusing on positive parenting showed a $19 \%$ decrease in the stigma associated with parents needing help in parenting. ${ }^{89}$

Legislative approaches to reduce corporal punishment. Evidence suggests that legislative approaches can impact the use of severe corporal punishment against children, the understanding of what constitutes violent punishment, and attitudes towards the use of such punishment. ${ }^{90-92}$ Findings from a multi-country study ${ }^{93}$ and a systematic review of the literature ${ }^{94}$ showed that legislative restrictions on corporal punishment in other countries have been closely associated with decreases in support of and use of corporal punishment as a child discipline technique. A comparison of five European countries, three of which had bans on corporal punishment and two without, ${ }^{93}$ found that bans were successful in decreasing overall rates of corporal punishment. Countries wherein corporal punishment was lawful had higher rates of all forms of corporal punishment than countries with bans in place. Moreover, acceptance of corporal punishment was lower in countries with bans on corporal punishment. ${ }^{93}$

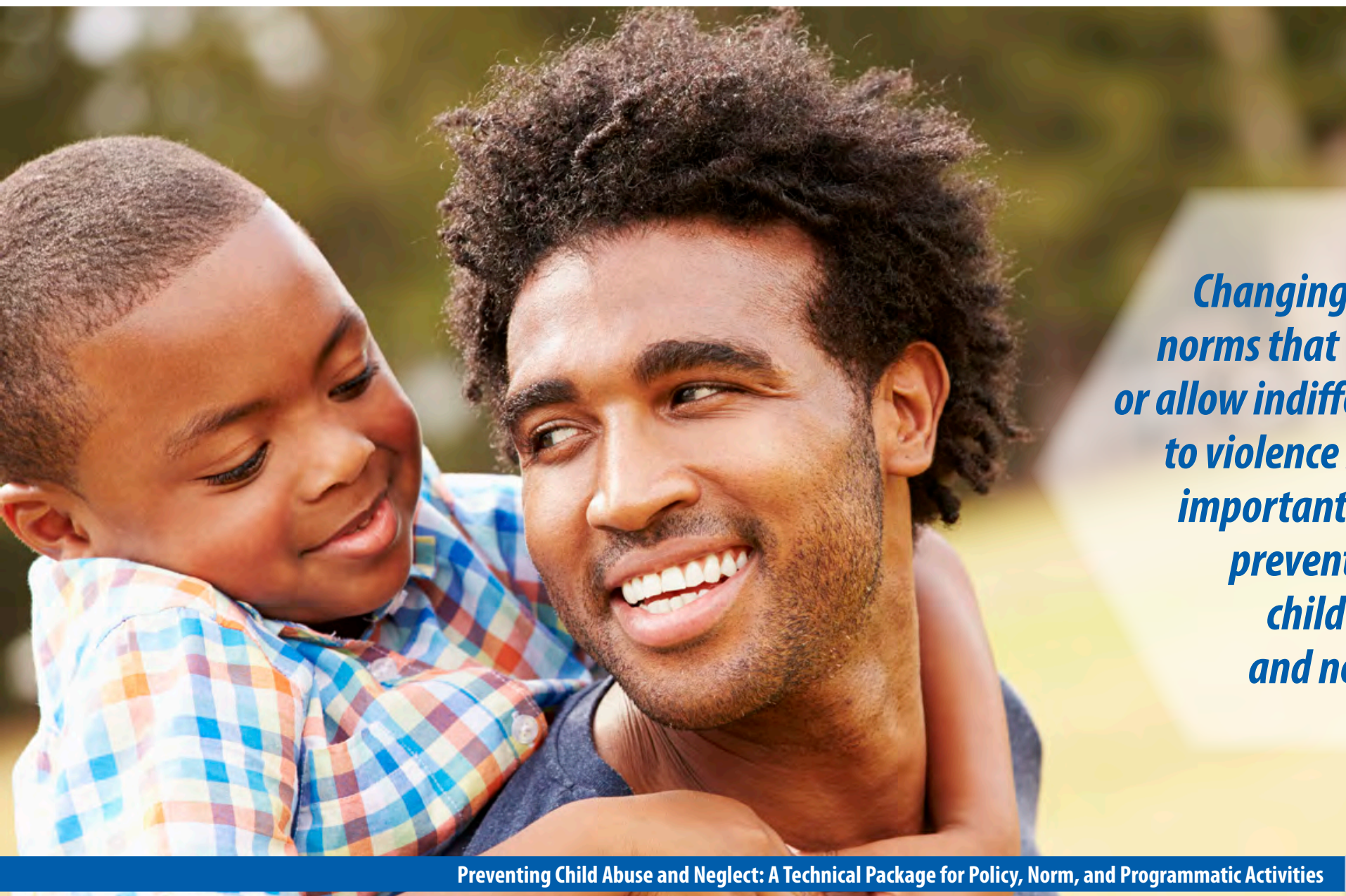




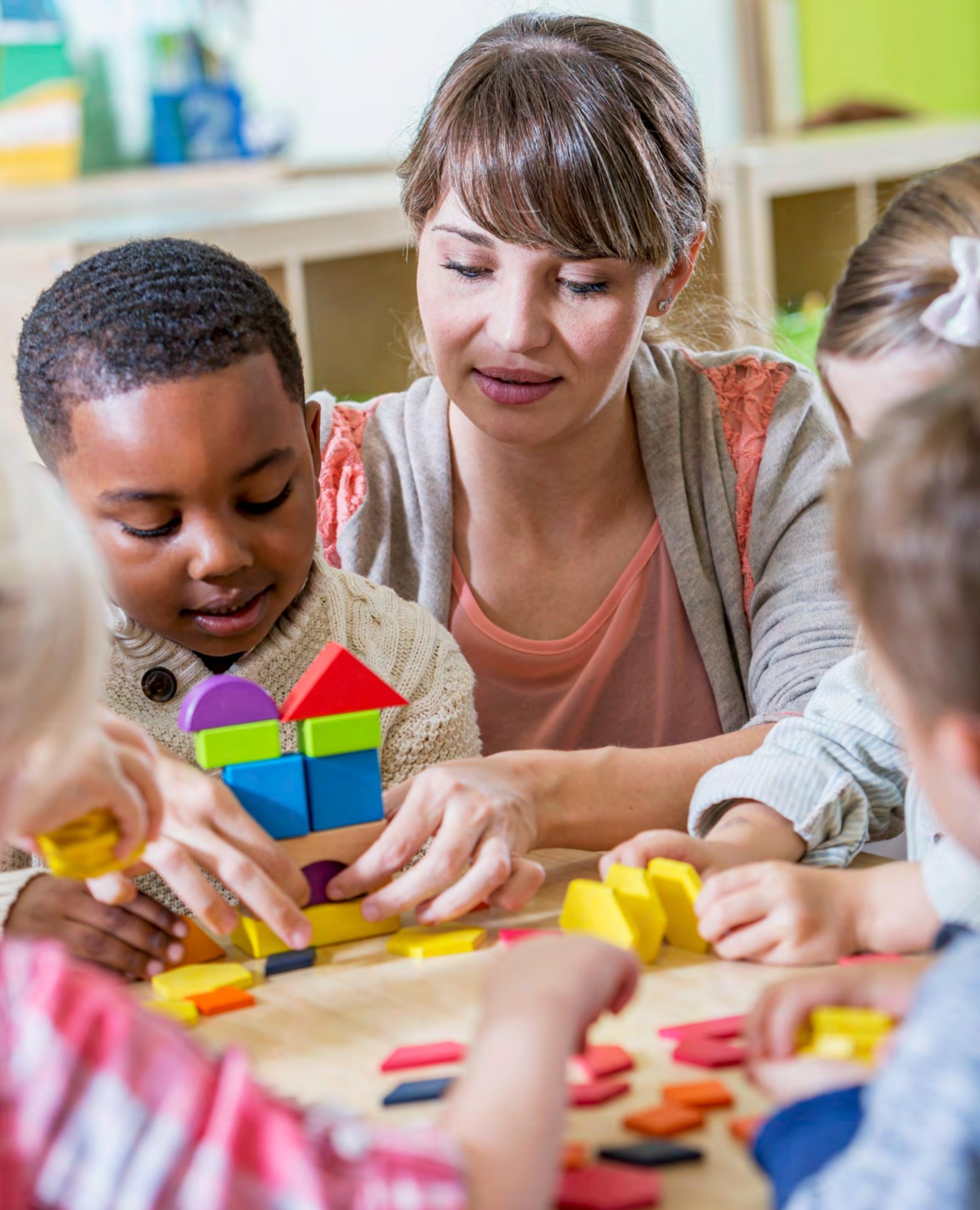




\section{Provide Quality Care and Education Early in Life}

\section{Rationale}

Quality child care and early childhood education can improve children's cognitive and socioemotional development and increase the likelihood that children will experience safe, stable, nurturing relationships and environments, both in the child care and education settings and at home. Past research has suggested that states meeting the demand for child care assistance ${ }^{68}$ and neighborhoods with more licensed child care spaces relative to child care need ${ }^{69}$ had lower rates of child abuse and neglect. Difficulties finding quality child care also are linked to increased rates of self-reported child neglect among substance abusing mothers. ${ }^{95}$ Access to affordable, quality child care is associated with reduced parental stress ${ }^{70}$ and maternal depression, ${ }^{71}$ both of which are risk factors for child abuse and neglect. ${ }^{37}$ Early childhood education that includes parent engagement can also enhance parenting practices and attitudes as well as family involvement in children's education. ${ }^{96}$ Parents also have opportunities to develop social connections to other parents. ${ }^{69}$ Moreover, attendance at quality and supportive schools, which are licensed and accredited, promotes social skill and cognitive development in children, making them less likely to exhibit challenging problem behavior at school and at home, which contributes to better scholastic achievement and less parental stress and conflict. ${ }^{97}$

\section{Approaches}

Preschool enrichment with family engagement and improved quality of child care through licensing and accreditation are two approaches for enhancing parenting practices, parental education, social support, and access to community resources, while simultaneously creating optimal learning environments for young children.

Preschool enrichment with family engagement programs provide high-quality early education and care to economically disadvantaged children to build a strong foundation for future learning and healthy development. These programs also provide support and educational opportunities for parents. Services are available to children and families provided they meet basic qualifications, such as being residents in a high-poverty school area eligible for federal Title I funding, demonstrate need, and agree to participate ${ }^{98}$ or having incomes at or below the federal poverty level. Parent involvement is emphasized as critical in the child's development and in increasing children's success in school. Programs often begin in infancy or toddlerhood and may continue into early or middle childhood.

Improved quality of child care through licensing and accreditation. Accredited child care ensures that the quality of children's daily experiences are positive and supportive. Based on research and the development of young children, the National Association for the Education of Young Children ${ }^{99}$ has identified program standards and criteria for accreditation, which are the quality indicators or characteristics believed to best promote child well-being and foster a safe, nurturing, and stimulating environment. These characteristics can help parents make better child care choices for their children because they indicate a much greater likelihood of high quality care. 


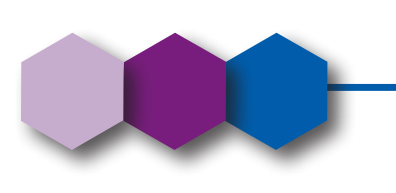

\section{Potential Outcomes}

- Reduced encounters with child welfare services

- Reduced physical and sexual violence against children

- Lower rates of out-of-home placement

- Higher rates of high school completion, college attendance and more years of completed education, lower drop-out rates

- Lower rates of juvenile arrests, felony arrests, incarceration

- Lower rates of grade retention and special education services

- Higher rates of health care coverage

- Lower rates of depressive symptoms

- Higher rates of full time employment

- Lower rates of disability

\section{Evidence}

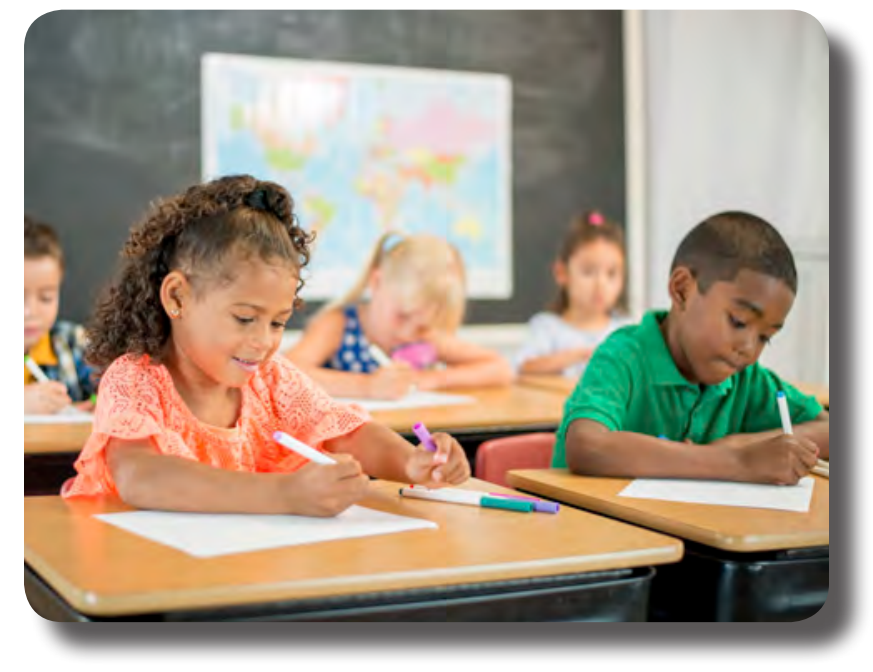

Evidence exists that preschool enrichment programs with family engagement and accredited child care can prevent child abuse and neglect and may provide other benefits to children and families, such as enhanced parent-child interactions.

Preschool enrichment with family engagement programs, in general, have documented positive impacts on the child's cognitive skills, school achievement, social skills, and conduct problems and are effective in reducing child abuse and neglect. The effects of one program, Child Parent Centers (CPC), were examined in a 15-year follow-up of a group of 1539 low-income minority children (93\% black, 7\% Hispanic). ${ }^{32}$ Since 1985, data have been collected yearly on educational and family experiences from school records and participant surveys. Relative to the preschool comparison group, children who participated in the CPC preschool intervention for 1 or 2 years had a $52 \%$ reduction in substantiated reports of child abuse and neglect, ${ }^{96}$ a higher rate of high school completion (49.7\% vs $\left.38.5 \%\right)$, and lower rates of juvenile arrest (16.9\% vs $25.1 \%)$, violent arrests (9.0\% vs $15.3 \%)$, and school dropout (46.7\% vs $55.0 \%)$ when followed to age $20 .{ }^{32}$ Both preschool and school-age participation in the CPCs were significantly associated with a 33\% reduction in substantiated child abuse and neglect, lower rates of grade retention and special education services. In a 19-year follow-up of the same cohort, ${ }^{100}$ CPC preschool participants (relative to the preschool comparison group) had higher rates of attendance in 4-year colleges (14.7\% vs $10.0 \%$ ) and were more likely to have health insurance coverage. Preschool graduates also had lower rates of felony arrests, convictions, incarceration, depressive symptoms, and out-of-home placements. Participation in both preschool and school-age intervention, relative to the comparison group, was associated with higher rates of full-time employment, higher levels of educational attainment, lower rates of arrests for violent offenses, and lower rates of disability. All of these outcomes amount to increased benefits to society. A recent study found that the preschool program provided a total return to society of $\$ 10.83$ per dollar invested (18\% annual return). ${ }^{101}$ While the return on investment was not as significant for the school age and extended intervention programs as for the preschool program, the return to society was still significant. ${ }^{101}$

Another preschool enrichment program with family engagement, Early Head Start (EHS), was evaluated in a randomized trial of 3,001 families via interviews with primary caregivers, child assessments, and observation of parentchild interactions. ${ }^{102}$ Three-year-old children who participated in EHS had better cognitive and language development and exhibited less aggressive behavior than control children, the latter of whom were able to access services in the community but were not provided EHS services. Parents of children enrolled in EHS were more emotionally supportive, provided more language and learning stimulation, read to their children more, and spanked less compared to control parents. EHS was also evaluated using child welfare administrative data collected retrospectively among a subset of participants $(n=1227)$ to establish its impact on child abuse and neglect. ${ }^{103}$ Results indicated that children in EHS had significantly fewer child welfare encounters between the ages of 5 and 9 than did children in the control group, and that EHS slowed the rate of subsequent encounters. Additionally, compared to children in the control group, children in EHS were less likely to have a substantiated report of physical or sexual abuse but more likely to have a substantiated report of neglect. ${ }^{103}$ As noted by Green et al., ${ }^{103}$ EHS likely did not increase rates of child neglect but rather enrollment in EHS may have increased the visibility of young children experiencing neglect. The increased rates of neglect may therefore be the result of increased monitoring of families receiving EHS services. 
Improved quality of child care through licensing and accreditation. Accredited child care, which ensures quality care, is associated with positive outcomes for children. For example, when compared to infants with easy temperaments, infants with difficult temperaments who received quality child care had fewer behavior problems than those provided lower quality child care. ${ }^{104}$ Other research suggests that quality child care can counteract a lower quality home environment. When children with lower quality home environments and high quality child care were compared to children with lower quality home and child care environments, fewer behavior problems (a risk factor for child abuse and neglect) ${ }^{37}$ were noted among the former group. ${ }^{105}$

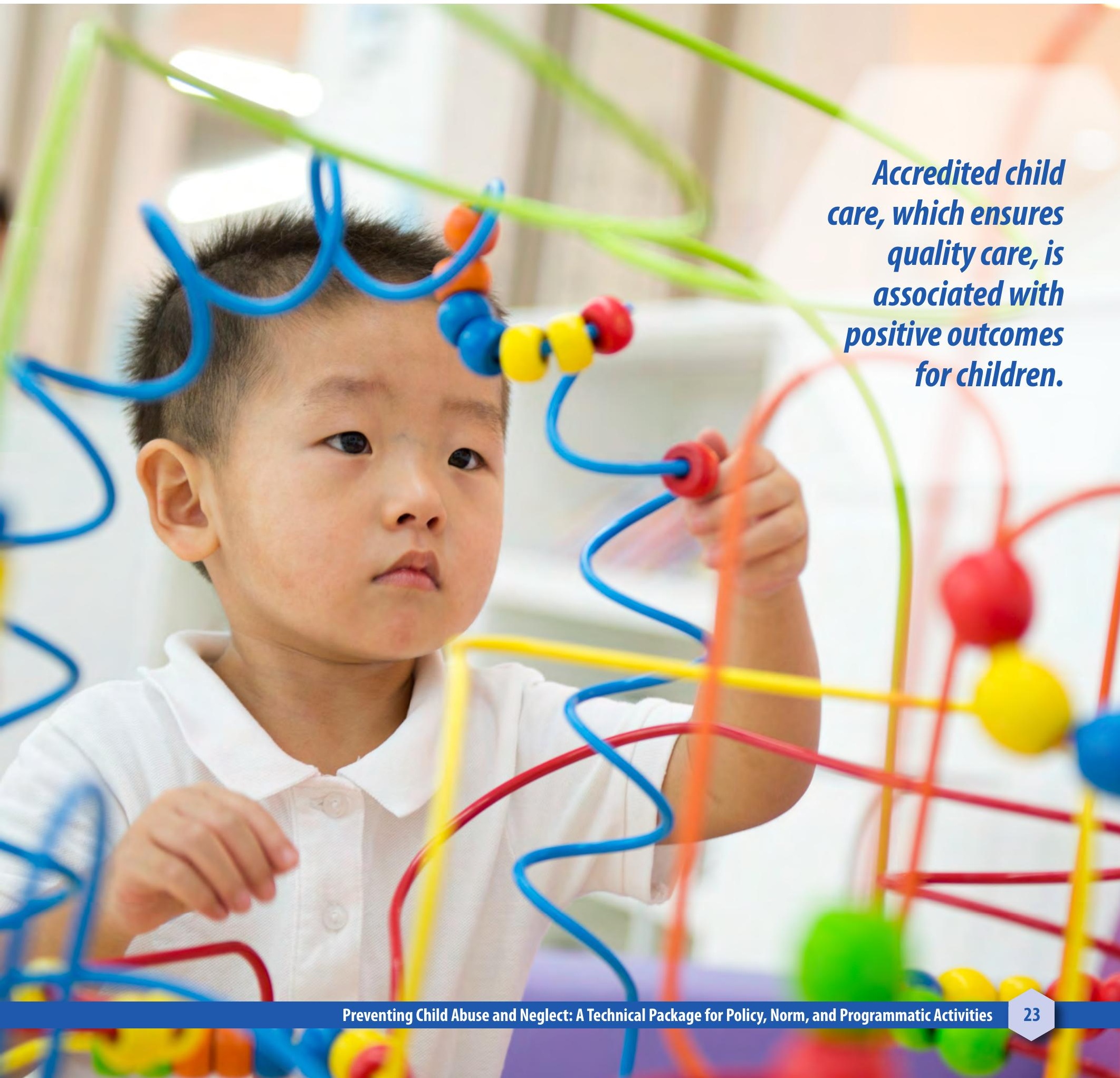





\section{Enhance Parenting Skills to Promote Healthy Child Development}

\section{Rationale}

A child's relationship with others inside and outside the family plays a role in healthy brain development, as well as in the development of physical, emotional, social, behavioral, and intellectual capacities. ${ }^{106}$ Parents who have inadequate parenting skills ${ }^{37}$ or are experiencing health or financial issues have more difficulty parenting and providing the care and nurturing that is needed for children to have safe, stable, nurturing relationships and environments. ${ }^{107,108}$ There is substantial evidence that parent training programs or behavioral family interventions delivered in clinical settings and focused on influencing children's behavior through positive reinforcement are effective at influencing the childrearing practices of families. ${ }^{109-111}$ Some evidence also suggests that these types of programs can prevent physical abuse and neglect. ${ }^{112}$ Although the focus may be different, the goal of each of these programs is to provide parents with skills that can be used to promote the health and well-being of the child.

\section{Approaches}

Several approaches seek to enhance parenting skills and promote healthy child development in ways that prevent child abuse and neglect.

Early childhood home visitation programs provide information, caregiver support, and training about child health, development, and care to families in their homes. Home visiting programs often differ depending on the model being utilized. Many programs, such as Nurse Family Partnership (NFP), are offered to low-income, first-time mothers as they are at higher risk for child abuse and neglect. ${ }^{113}$ Other home visiting programs, such as Durham Connects, are offered to all new parents in certain geographical regions. ${ }^{114}$ Home visiting programs may be delivered by nurses, professionals, or paraprofessionals. The content of programs varies depending on the model being utilized, with some being highly manualized (e.g., NFP) and others being more flexible in content delivery (Healthy Families), ${ }^{115}$ and the point at which the program begins varies depending on the model. Some programs begin during pregnancy, while others begin after the birth of the child. ${ }^{115}$

Parenting skill and family relationship approaches provide parents and caregivers with support and teach behavior management and positive parenting skills to build strong and safe families that protect children from violence and its long-term consequences. ${ }^{116,117}$ Programs may be targeted to parents of children in a specific age range or for parents in general. ${ }^{116}$ Parents typically receive information about child development and the causes and consequences of violence, anger management skills, problem-solving skills, and discipline techniques not involving physical punishment. ${ }^{116}$ 


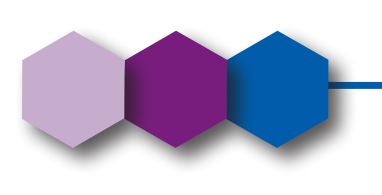

\section{Potential Outcomes}

- Reductions in child abuse and neglect perpetration

- Reductions in risk factors for child abuse and neglect (e.g., parental substance use, criminal involvement, timing of subsequent births, child behavioral problems)

- Improved parent-child interactions (e.g., increased nurturing)

- Improved parenting behaviors (e.g., child behavior management), including reductions in use of harsh verbal and physical discipline

- Improved violence prevention-related knowledge, behaviors, and beliefs

- Fewer emergency room visits and hospital stays

- Reductions in use of welfare

- Reductions in criminal behavior

- Reductions in youth substance use and arrests

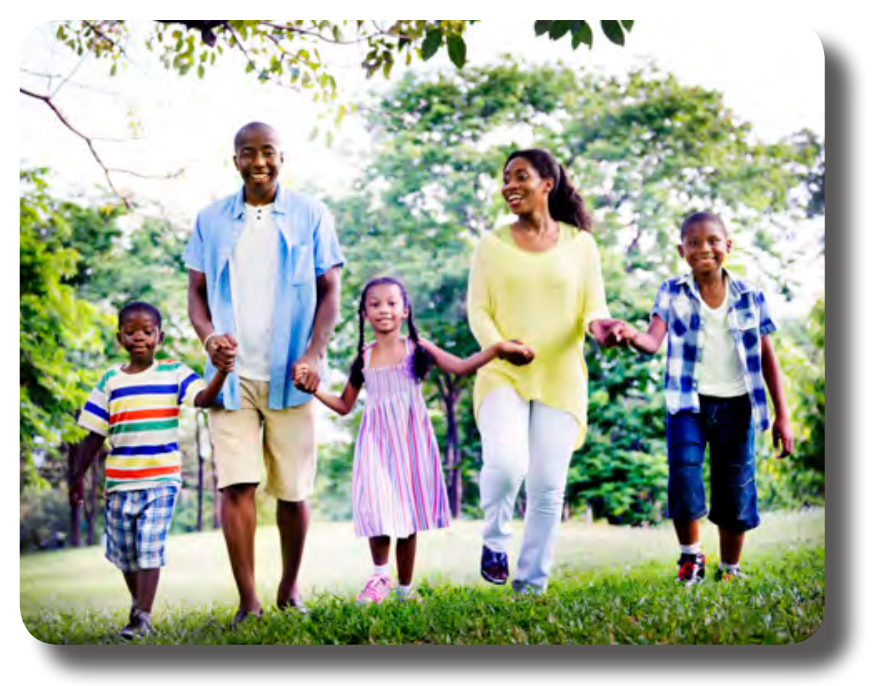

\section{Evidence}

Approaches that enhance parenting skills and promote healthy child development have demonstrated effects in preventing child abuse and neglect, although the level of effectiveness varies by model and program.

Early childhood home visitation. The evidence of effectiveness for home visiting programs is mixed, with some models showing few or no effects and others showing strong effects. ${ }^{118-120}$ These mixed effects likely arise because the content of home visiting models varies. The Nurse Family Partnership (NFP) program, for example, has documented a $48 \%$ relative reduction in child abuse and neglect, as well as reductions in risk factors (e.g., parental substance use, timing of subsequent births, child behavioral problems) associated with child abuse and neglect. ${ }^{24}$ The NFP program also reduced the number of subsequent pregnancies, the use of welfare, and criminal behavior in women who participated in the home visiting program, when compared to women in the comparison group. ${ }^{24,121}$ Moreover, reductions have been noted in substance use and arrests among the children who participated in NFP. ${ }^{30}$ Reductions in child protective services reports also have been documented up to three years for families in the Netherlands receiving NFP compared to those receiving usual care. ${ }^{122}$ At 6-months, Durham Connects, a home visiting program wherein nurses assess health and psychosocial risk across four domains and 12 factors, documented fewer emergency medical care episodes, and more community connections, more positive parenting behaviors, participation in higher quality out-of-home child care, and lower rates of anxiety than control mothers, as well as higher quality home environments compared to controls. ${ }^{123}$ At 12-months, 50\% fewer total emergency medical care use was documented for Durham Connects families relative to controls. ${ }^{124}$ The Home Visiting Evidence of Effectiveness Review ${ }^{120}$ identifies other home visiting models that may work for communities, depending on available resources and the context in which the home visiting model is delivered.

Parenting skill and family relationship approaches. Parenting skill training approaches have consistently demonstrated positive effects in preventing child abuse and neglect. One program, Adults and Children Together Against Violence: Parents Raising Safe Kids (ACT), which teaches positive parenting skills, documented reductions in the use of harsh verbal and physical discipline and an increase in nurturing behavior at post-treatment and at a threemonth follow-up. ${ }^{117}$ In other research, significantly lower instances of spanking and hitting children with objects were observed among those who received the training when compared to a group who did not receive the training. ${ }^{116}$ Significant improvements were also observed from baseline to post-treatment for parents who received the training in violence prevention-related knowledge, behaviors, and beliefs as well as parenting skills. ${ }^{116}$ 


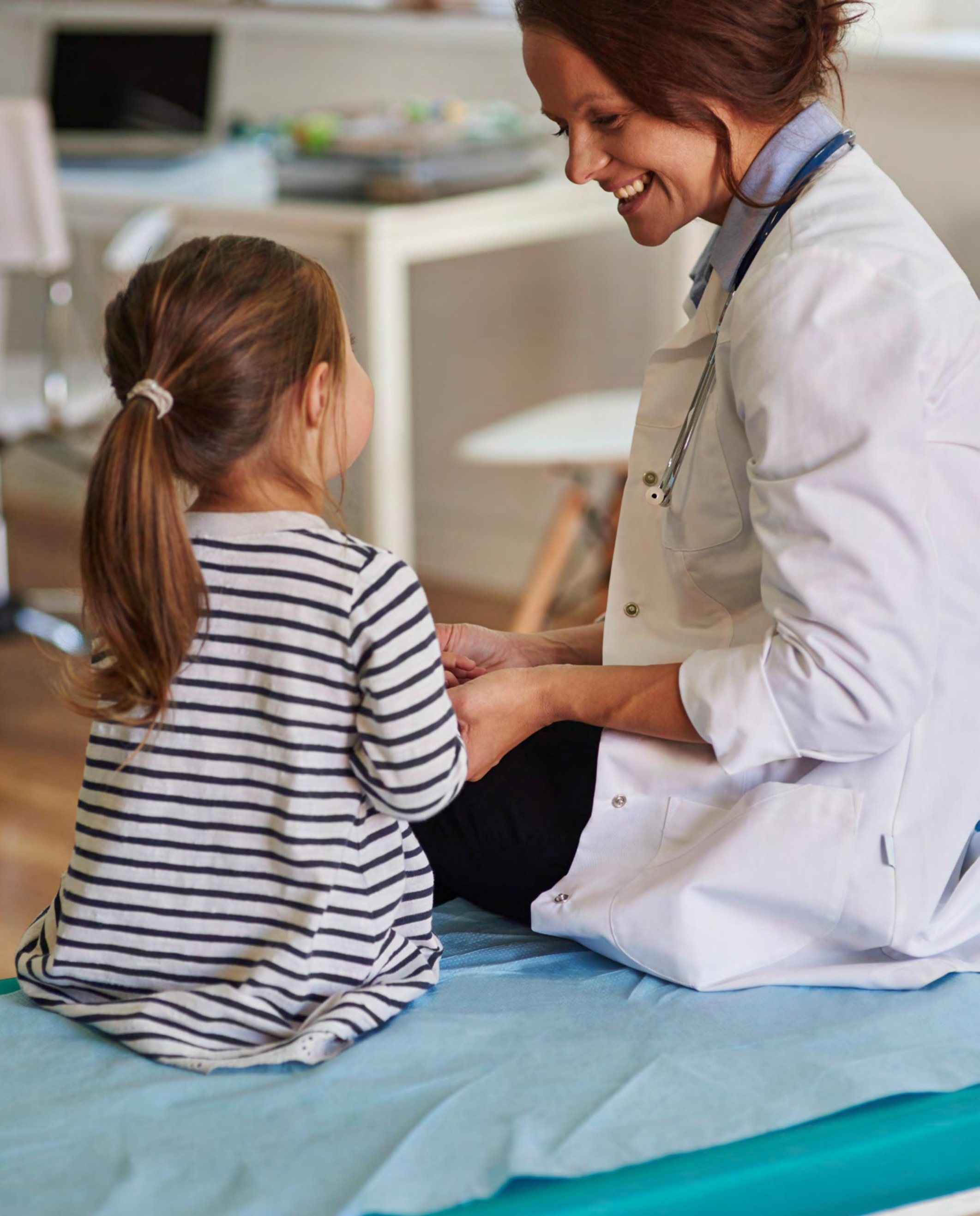




\section{Intervene to Lessen Harms and Prevent Future Risk}

\section{Rationale}

Exposure to child abuse and neglect negatively impacts short- and long-term mental and physical health and wellbeing, as well as biological systems and structures. ${ }^{15,36,129,130}$ Moreover, children with histories of abuse and neglect are at risk of perpetrating maltreatment and other types of violence as adults and are at risk of future and multiple victimization experiences. ${ }^{131-135}$ Some evidence suggests that behavioral parent training programs can prevent the recurrence of physical abuse and neglect. ${ }^{27,28}$ These programs are often focused on those who have demonstrated risk factors for physical abuse and neglect, such as contact with the child welfare system. In instances when abuse and neglect have occurred and symptoms such as behavior problems, posttraumatic stress, anxiety, and depression are present in the child, the symptoms can be treated successfully with evidence-based treatment programs. ${ }^{136}$ Thus, it stands to reason that treatment of children and families in which abuse has occurred may work to mitigate the health consequences of child abuse and neglect exposure, prevent recurrence of child abuse and neglect, decrease the risk for other types of violence later in life, and decrease the likelihood that individuals will abuse their own children later in life.

\section{Approaches}

Several approaches have been identified to prevent abuse and neglect, its recurrence, and the negative outcomes associated with abuse and neglect. The approaches described below serve to intervene to lessen harms and prevent future risk posed by child abuse and neglect exposure or its associated risk factors.

Enhanced primary care may be used to identify and address psychosocial problems in the family that serve as risk factors for child abuse and neglect. Primary care providers are trained to identify and address factors (e.g., parental depression, substance abuse, major stress, utilization of harsh punishment, intimate partner violence) that increase risk for child abuse and neglect. ${ }^{137}$ Follow-up is often conducted with a social worker to address problems and/or provide referrals to community resources. Parents also receive handouts that include information on problems addressed with the social worker, as well as information on local resources. ${ }^{137}$

Behavioral parent training programs may reduce the recurrence of child abuse and neglect while teaching parents specific skills to build a safe, stable, nurturing relationship with their children. Behavioral parent training programs are typically delivered to a single family or a group of families in a structured format over the course of about 12-16 sessions. Children targeted by the programs usually range in age from 0 to 12 , although the specific age range is dependent on the model chosen. Topics covered in these programs often range from parent-child interactions and relationship enhancement skills to child behavior management and discipline skills.

Treatment for children and families to lessen the harms of abuse and neglect exposure. Therapeutic treatment can mitigate the health consequences of abuse and neglect exposure, decrease the risk for other types of violence later in life, and decrease the likelihood that individuals will abuse their own children. These treatments are typically delivered by trained professionals in a 1-1 or group setting and over the course of 12 or more sessions. Treatment is often provided to children at varying ages and stages of development, and as such, may engage both the child and parent in the treatment process.

Treatment for children and families to prevent problem behavior and later involvement in violence. Therapeutic treatments are typically delivered by highly trained professionals in a 1-1 or group setting and over the course of several months. Given the focus on youth and the role of parents and caregivers in monitoring and guiding the child's behavior, parents and caregivers are often included in the treatment process or the child's entire social network may be engaged. Children of all ages may participate in these programs, although the specific age of children targeted often depends on the specific program being implemented. 
- Fewer delayed immunizations

- Reductions in abuse and neglect perpetration

- Reductions in short- and long-term trauma-related symptoms of the child, including internalizing (e.g., posttraumatic stress, depression, anxiety) and externalizing (e.g., sexualized behaviors, aggressive behavior) symptoms

- Improved parent-child interactions, parenting behaviors, and family functioning

- Reductions in parental depression, emotional distress, and substance use

- Decreased number of and time spent in out-of-home placements

- Reductions in substance use among youth

- Reductions in re-offending

\section{Evidence}

A large body of evidence highlights the importance of intervening with those who have experienced and those at risk of perpetrating abuse and neglect. Abuse and neglect often tend to be cyclical; thus, success in interrupting the cycle of violence can prevent the exposure of many children to abuse and neglect.

Enhanced primary care programs, such as the Safe Environment for Every Kid (SEEK) model, have demonstrated positive effects on child abuse and neglect. For example, families who participated in the SEEK program had fewer reports to child protective services than families who completed services as usual $(13.3 \%$ and $19.2 \%$, respectively); reported fewer occurrences of severe physical assault (average weighted score: 0.11 and 0.33 , respectively); and were more likely to adhere to medical care $(4.6 \%$ and $8.4 \%$, respectively) and ensure their children had timely immunizations (3.3\% and 9.6\%, respectively). ${ }^{137}$ SEEK also resulted in less maternal psychological aggression (effect size $=-0.16)$ and fewer minor maternal physical assaults (effect size $=-0.16) .{ }^{138}$

Behavioral parent training programs such as Parent-Child Interaction Therapy (PCIT), The Incredible Years, and SafeCare demonstrate success in preventing recidivism for abuse in families with substantiated cases of child abuse and neglect, and in reducing child abuse and neglect risk factors in high-risk families (e.g., those who use harsh/ punitive parenting practices). ${ }^{27,28,139-141} \mathrm{~A}$ study conducted with parents reported to CPS found fewer re-reports of physical abuse and/or neglect at a 36-month follow-up for parents who completed SafeCare (15\% recidivism) than families who completed services as usual (46\% recidivism). ${ }^{142}$ Physically abusive parents in the child welfare system who participated in PCIT had significantly fewer re-reports of physical abuse than parents who participated in services as usual (19\% vs 49\%). ${ }^{27}$ In a study of families with chronic and severe neglect and/or physical abuse histories, PCIT plus a motivational enhancement was effective in reducing future child welfare reports, with a stronger effect observed when children were returned to the home sooner rather than later. ${ }^{28}$ The Incredible Years is effective in reducing harsh parenting and conduct problems and increasing positive discipline and nurturing parenting. ${ }^{143}$ In a study of primarily neglectful biological and foster parents, positive parenting skills increased for parents who participated in The Incredible Years program (when compared to controls), and the improvements were greatest when parents attended six or more sessions..$^{144}$

Treatment for children and families to lessen the harms of abuse and neglect exposure, such as Trauma-Focused Cognitive Behavioral Therapy (TF-CBT), is effective in reducing symptoms of posttraumatic stress disorder (PTSD), depression, and behavior problems at post-treatment and for PTSD at 12 months post-treatment. ${ }^{145}$ Other research has suggested that post-treatment improvements in trauma-related symptoms for the child (e.g., posttraumatic stress, depression, fear, sexualized behavior, anxiety, shame, behavioral issues) are sustained at 6 and 12 months posttreatment, as are parenting-related behaviors and parental emotional distress and depressive symptoms. ${ }^{146}$ 
Treatment for children and families to prevent problem behavior and later involvement in violence often address the behavioral consequences of experiencing child abuse and neglect. The effectiveness of the Children with Problematic Sexual Behavior Cognitive-Behavioral Treatment Program: School-age Program was examined in a 10-year prospective study of 135 children aged 5-12 with sexual behavior problems and significant reductions in re-offending were noted for the CBT treatment group when compared to a play therapy group ( $2 \%$ vs $10 \%) .{ }^{147}$ In a comparison of this same group of children to a general clinic comparison, no differences were noted between groups in nonsexual offenses. ${ }^{147}$ In other research, CBT resulted in improvements in child sexual behavior problems at post-treatment and/ or follow-up. ${ }^{148,149}$ Another program, Multisystemic Therapy (MST), is an intensive treatment program designed for chronic and violent juvenile offenders 12 to 17 years of age. The program engages the child's entire social network (e.g., family, school and teachers, neighborhood and friends) as a means of preventing problem behavior and later involvement in violence. ${ }^{150}$ The program is associated with improved parent-child interactions, decreased symptoms for the youth and caregiver, improved parenting behaviors, increased social support, and decreased out-of-home placements (63\% fewer days). ${ }^{151-153}$ Moreover, at a 24-month follow-up, decreases were observed in rates of child maltreatment and time youth spent in out-of-home placements. ${ }^{153} \mathrm{~A}$ recent meta-analysis of the effects of MST found small but significant treatment effects on delinquency, psychopathology, substance use, family factors, out-of-home placement and peer factors. ${ }^{154}$
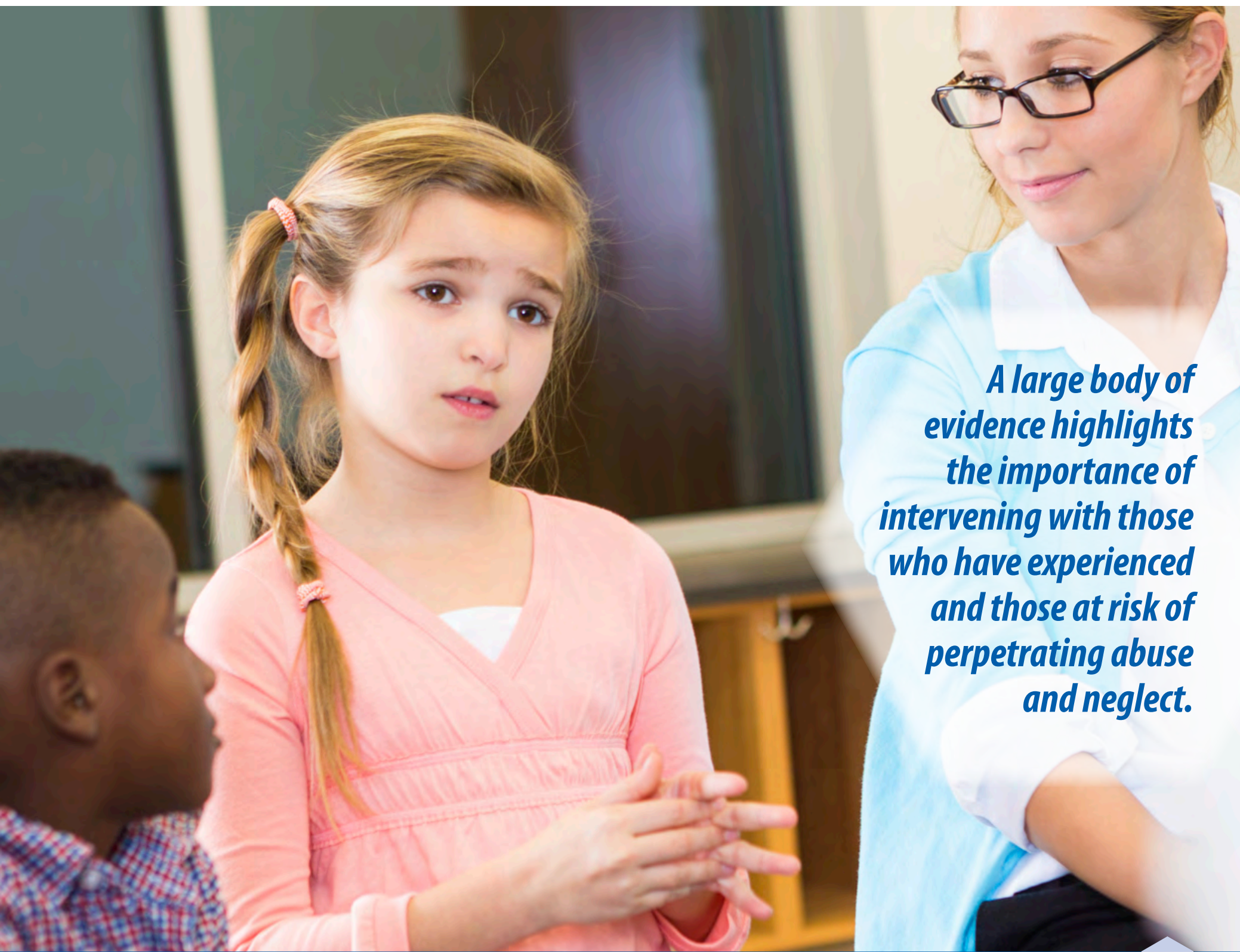

A large body of evidence highlights the importance of intervening with those who have experienced and those at risk of perpetrating abuse and neglect. 


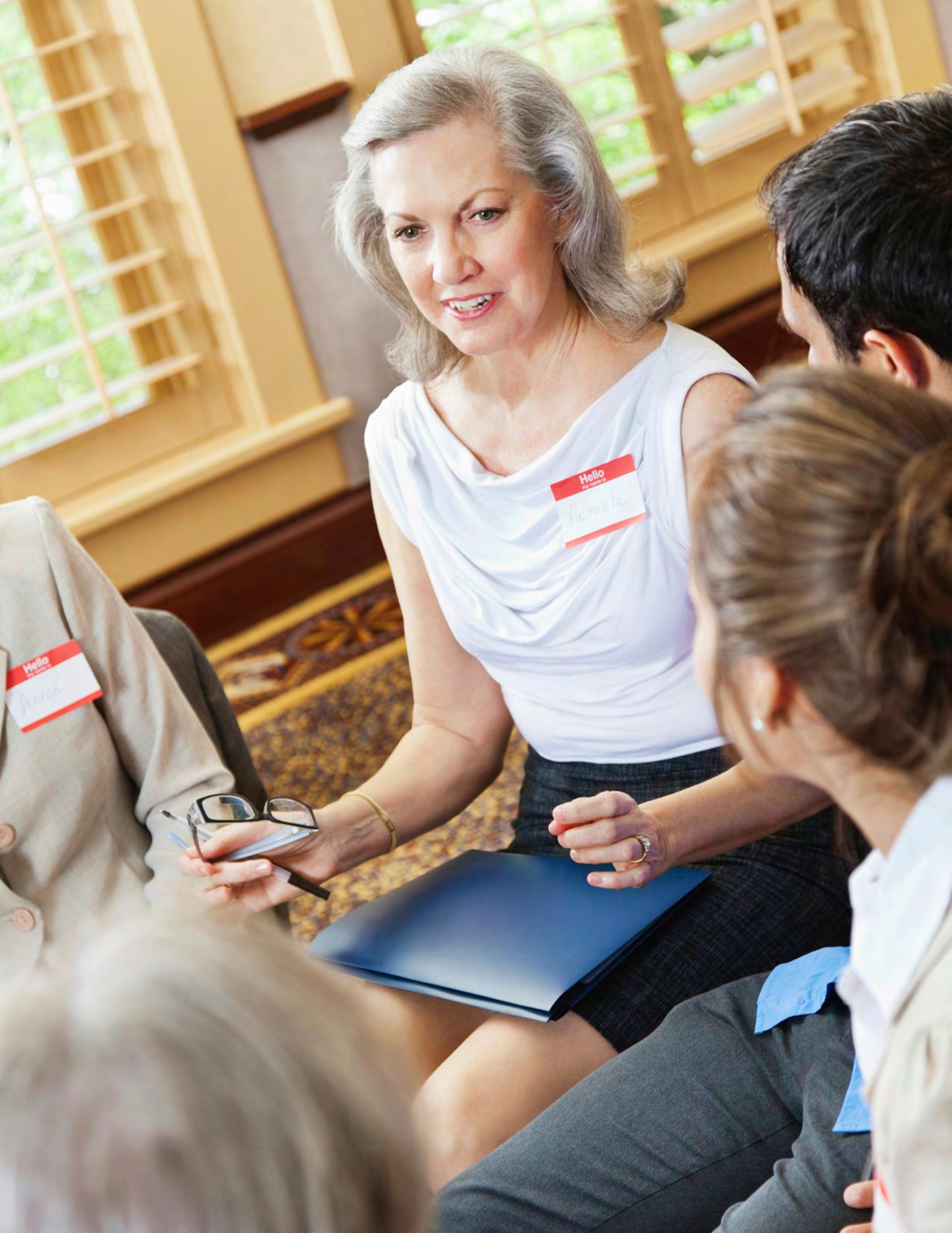




\section{Sector Involvement}

Public health can play an important and unique role in addressing child abuse and neglect. Public health agencies, which typically place prevention at the forefront of efforts and work to create broad population-level impact, can bring critical leadership and resources to bear on this problem. For example, these agencies can serve as a convener, bringing together partners and stakeholders to plan, prioritize, and coordinate child abuse and neglect prevention efforts. Public health agencies are also well positioned to collect and disseminate data, implement preventive measures, evaluate programs, and track progress. Although public health can be a lead in preventing child abuse and neglect, the strategies and approaches outlined in this technical package cannot be accomplished by the public health sector alone.

Other sectors vital to implementing this technical package include, but are not limited to, education, government (local, state, and federal), social services, health services, business/labor, justice, housing, media, and organizations that comprise civil society such as faith-based organizations, youth-serving organizations, foundations and other non-governmental organizations. Collectively, these sectors can make a difference in preventing child abuse and neglect by impacting the various contexts that contribute to and support safe, stable, nurturing relationships and environments for children.

The strategies and approaches described in this technical package are summarized in the Appendix, along with the relevant sectors that are well positioned to lead implementation efforts. For example, business/labor and government entities are in the best position to implement programs and policies that Strengthen Economic Supports for Families. These types of supports go beyond individual behavior change and require commitment and support from those sectors that can directly address some of the underlying risks and the environmental contexts that increase the likelihood of child abuse and neglect. Public health entities can play an important role by gathering and synthesizing information to inform policy, raise awareness, and evaluate the effectiveness of various policies. Moreover, partnerships with non-governmental and community organizations can be instrumental in increasing awareness of and garnering support for policies affecting children and families.

The public health sector has been at the forefront of many public engagement and education campaigns focused on changing social norms and positively impacting health behavior (e.g., drinking and driving, smoking cessation, and nutrition). It is well suited to take on a similar leadership role in changing social norms in support of parents and positive parenting to prevent child abuse and neglect. Legislative approaches to reduce corporal punishment, on the other hand, fall within the realm of local, state, and federal legislative bodies. These are the entities which draft and enact legislation. Similar to other policy changes, public health can be helpful in gathering information to inform policy, including research on policy alternatives and their impact, working with other agencies within the executive branch of their state or local governments on implementation of policies, and evaluating the effectiveness of measures taken.

The social services and public health sectors are vital for implementation and continued provision of Quality Care and Education Early in Life. As the lead sector in implementing programs such as Child-Parent Centers and Early Head Start throughout the country, the social services sector is helping to ensure that families and communities receive the skills and services necessary to promote the physical, cognitive, social, and emotional development of young children, thereby preparing them for future growth and development. Business/labor and government entities are in the best position to ensure Quality Care through licensing and accreditation. Public health can assist by educating communities and other sectors about the importance of ensuring a comprehensive integrated array of quality child care and early childhood education services and supports for families to prevent child abuse and neglect and improve health outcomes across the life span. The public health sector can work with communities to complete a community health assessment to better identify gaps in services and the highest burden of child abuse and neglect within the community. The public health sector can also play a vital role in continuing research that documents the benefits of quality child care and early childhood education on child health and development, family well-being, and child abuse and neglect prevention, as this evidence is important in making the case for continued support of these programs for children and families in need. 


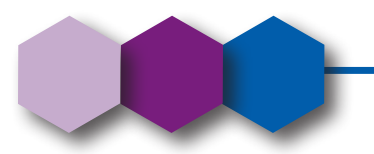

Finally, the technical package includes a number of approaches to Enhance Parenting Skills to Promote Healthy Child Development and Intervene to Lessen Harms and Prevent Future Risk of child abuse and neglect. The health care, public health, justice, and social services sectors can work collaboratively to identify and assist at-risk families and those for whom abuse and neglect is already present. In addition to having licensed providers trained to recognize and address risk factors for child abuse and neglect, the health care sector can coordinate wrap-around behavioral health and social services to address the health consequences of abuse and neglect and the conditions that may put the family at risk of recidivism.

Regardless of strategy - action by many sectors - will be necessary for the successful implementation of this package. In this regard, all sectors can play an important and influential role in supporting safe, stable, nurturing relationships and environments and preventing child abuse and neglect.

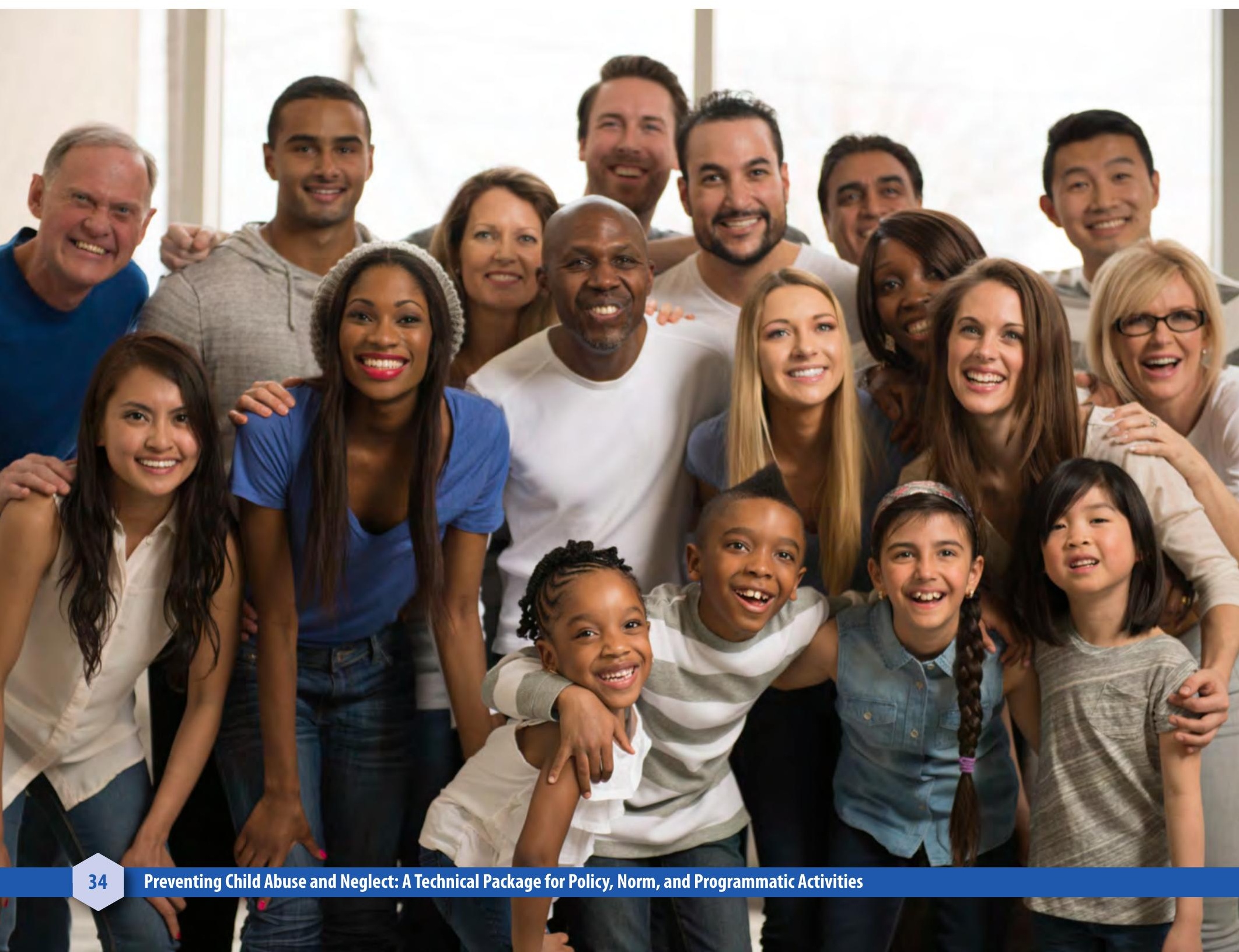




\section{Monitoring and Evaluation}

Monitoring and evaluation are necessary components of the public health approach to prevention. Timely and reliable data are necessary to monitor the extent of the problem and to evaluate the impact of prevention efforts. Data also are necessary for program implementation, as planning, implementation, and assessment all rely on accurate measurements of the problem.

In order to collect the most accurate information on the magnitude of child abuse and neglect and on the impact of implemented programs, practices, and policies, data collection should adhere to three key parameters: (1) uniform surveillance definitions should be used across disciplines; (2) case definitions should be applied consistently across data collection sites; and (3) data collection should occur on a regular, ongoing basis. Child abuse and neglect has long been examined through a social service and child protection lens, but incidents of child abuse and neglect often come to the attention of multiple agencies and sectors, including legal and medical communities, researchers, practitioners, advocates, and public health officials. As such, it is common for each agency and sector to employ unique definitions, thereby limiting communication across disciplines and hampering efforts to identify, assess, track, treat, and prevent child abuse and neglect effectively.

Surveillance data help researchers and practitioners track changes in the burden of child abuse and neglect. Surveillance systems exist at the federal, state, and local levels. It is important to assess the availability of surveillance data and data systems across these levels to identify and address gaps in the systems. At the federal level, the National Child Abuse and Neglect Data System (NCANDS) is an example of a surveillance system that provides data for child abuse and neglect. The NCANDS is a voluntary data collection system that gathers information from all 50 states, the District of Columbia, and Puerto Rico about reports of child abuse and neglect made to Child Protective Services. NCANDS was established in response to the Child Abuse Prevention and Treatment Act of 1988, and the data are used to examine trends in child abuse and neglect across the country. Key findings are published in the Child Welfare Outcomes Reports to Congress and annual Child Maltreatment reports.

Data from state or local Child Death Review teams offer another source to identify deaths in which child abuse and neglect caused or contributed to the fatality and to obtain insight into gaps in services, systems, and modifiable risk factors. Information from these reviews can be used at the local, state, and federal levels to focus planning and policy development, quality improvement and health systems development, and to enhance efforts to develop and maintain risk reduction and prevention programs for child abuse and neglect. ${ }^{155}$

While NCANDS provides official reports of child abuse and neglect, the National Survey of Children's Exposure to Violence (NatSCEV) provides self-reported data on violence against children through a nationally representative random-digit dial survey of children (0-9) and youth (10-18). Youth report on their own victimization experiences (over 50 forms of victimization assessed for the past 12 months and over the lifetime) across five general areas (i.e., conventional crime, child abuse and neglect, peer and sibling victimization, sexual victimization, and witnessing violence). Caregivers report on these victimizations for children. Of course, state estimates of child abuse and neglect are as important as national estimates. As such, monitoring of child abuse and neglect at the state level is critical if we are to understand the magnitude of the uptake of prevention strategies and their impact. No matter the data source specified, it is important that routine and ongoing monitoring align with the work of multiple federal, state-level, and local partners and agencies so that we may achieve a more comprehensive understanding of the problem and effective prevention efforts in this area.

It is also important to track progress of prevention efforts and to evaluate the impact of those efforts, including the impact of this technical package. Evaluation data, produced through program implementation and evaluation, is essential in providing information on what does or does not work to reduce rates of child abuse and neglect and associated risk and protective factors. 


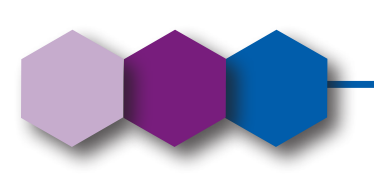

Much progress has been made in recent years to build the evidence base for child abuse and neglect prevention through research. However, additional research is needed to expand the inventory of effective child abuse and neglect prevention strategies, as well as the evidence base for protective factors that exist in individuals, families, and communities and risk factors that go beyond the individual and family. Prevention practitioners play a large role in building the evidence base by evaluating programs for impact on rates of child abuse and neglect and risk and protective factors. The field will advance if research continues to test programs born out of the field for effectiveness and identifies and tests programs for priority populations. Research is also needed on the impact of community and societal strategies, including policies and community environmental change, to reduce rates of child abuse and neglect and increase safe, stable, nurturing relationships and environments for children and families. Lastly, it will be important for researchers to test the effectiveness of combinations of the strategies included in this technical package.

\section{Conclusion}

Child abuse and neglect is a serious public health issue with far-reaching consequences for the youngest and most vulnerable members of society. Every child in the United States is better when he/she and his/her peers have safe, stable, nurturing relationships and environments. Thus, we all have a vested interest in ensuring that other children, not just our own, have safe, stable, nurturing relationships and environments. This technical package includes strategies and approaches that ideally would be used in combination in a multi-level, multi-sector approach to prevent child abuse and neglect. It includes strategies and approaches that are in keeping with CDC's emphasis on primary prevention, or preventing child abuse and neglect from happening in the first place, as well as approaches to lessen the short- and long-term harms of child abuse and neglect. The hope is that multiple sectors, such as public health, health care, education, justice, social services, and business will use this technical package as a guide and join CDC in efforts to prevent child abuse and neglect and its consequences. Each of the strategies and approaches that have been identified is supported by research that directly reduces child abuse and neglect or reduces the risk factors for child abuse and neglect. This technical package is designed with the intent that monitoring and evaluation will play a key role in implementation, and as new evidence related to a strategy or approach emerges in the literature, the technical package can be refined to reflect the most current knowledge to date in the field.

While child abuse and neglect is a significant public health problem, it is also a preventable one. The policy, norm, and programmatic strategies and approaches identified herein are intended to help guide the creation of neighborhoods and communities where every child has safe, stable, nurturing relationships and environments and a world where every child can thrive.

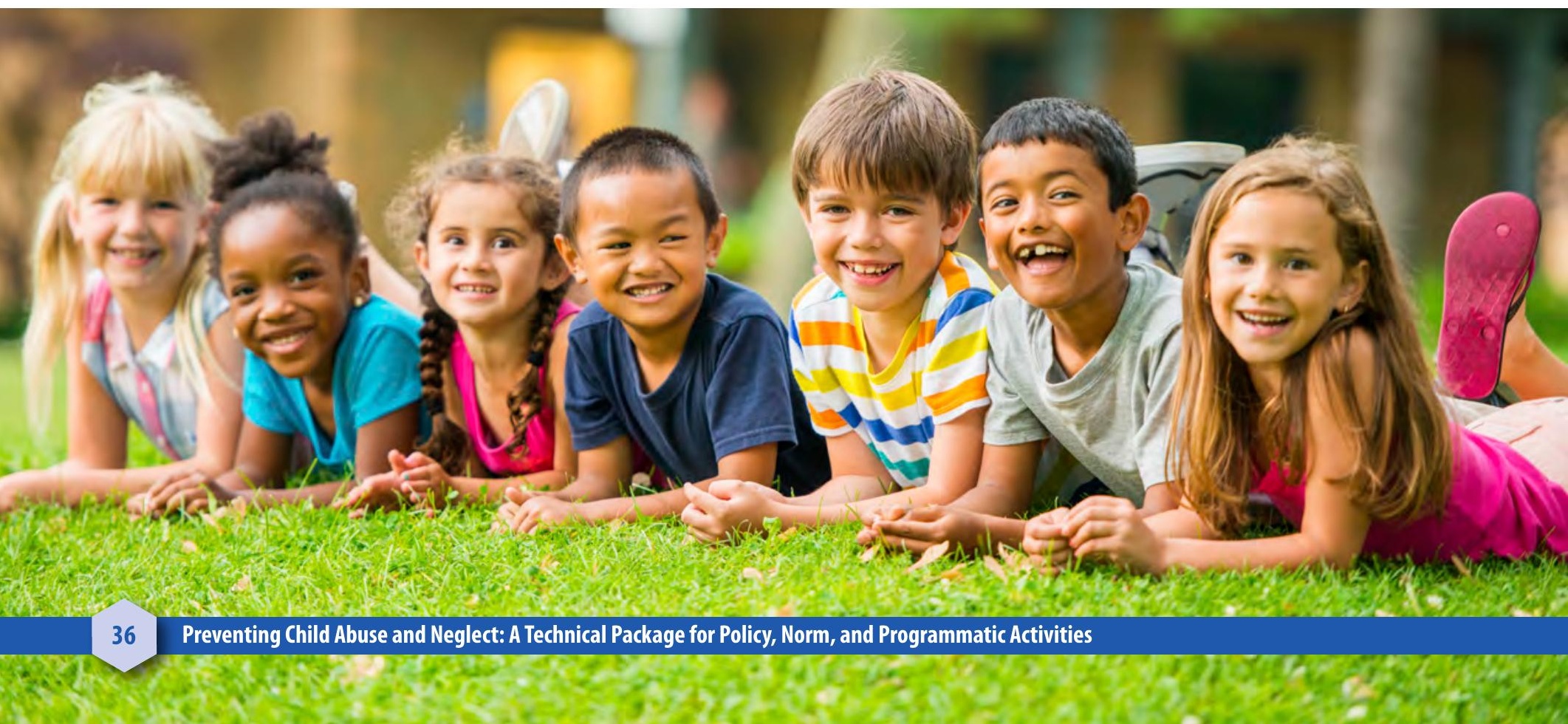




\section{References}

1. Daro, D., \& Dodge, K. A. (2009). Creating community responsibility for child protection: Possibilities and challenges. Future of Children, 19(2), 67-93.

2. Frieden, T. R. (2014). Six components necessary for effective public health program implementation. American Journal of Public Health, 104(1), 17-22.

3. Leeb, R. T., Paulozzi, L., Melanson, C., Simon, T., \& Arias, I. (2008). Child maltreatment surveillance: Uniform definitions for public health and recommended data elements, version 1.0. Atlanta, GA: Centers for Disease Control and Prevention, National Center for Injury Prevention and Control. Retrieved from http://www.cdc.gov/ViolencePrevention/pub/CMPSurveillance.html.

4. Finkelhor, D., Turner, H. A., Shattuck, A., \& Hamby, S. L. (2015). Prevalence of childhood exposure to violence, crime, and abuse: Results from the National Survey of Children's Exposure to Violence. JAMA Pediatrics, 169(8), 746-754.

5. United States Department of Health and Human Services (DHHS), Administration for Children and Families. (2015). Child maltreatment 2013. Washington, DC: Government Printing Office. Retrieved from http://www.acf.hhs.gov/sites/default/files/ $\mathrm{cb} / \mathrm{cm} 2013 . p d f$.

6. Sedlak, A. J., Mettenburg, J., Basena, M., Petta, I., McPherson, K., Greene, A., \& Li, S. (2010). Fourth National Incidence Study of Child Abuse and Neglect (NIS-4): Report to Congress, executive summary. Washington, DC: U.S. Department of Health and Human Services, Administration for Children and Families.

7. Centers for Disease Control and Prevention. (2015). Child maltreatment: Risk and protective factors. Retrieved from http:// www.cdc.gov/violenceprevention/childmaltreatment/riskprotective factors.html.

8. Development Services Group. (2015). Develop a protective factors framework for ACYF. Retrieved from http://www.dsgonline. com/ACYF.

9. Merrick, M. T., Fortson, B. L., \& Mercy, J. A. (2015). The epidemiology of child maltreatment. In P. D. Donnelly \& C. L. Ward (Eds.), Oxford textbooks in public health - Violence: A global health priority. Oxford, UK: Oxford University Press.

10. Fortson, B. L., \& Mercy, J. (2012). Violence against children. In J. M. Rippe (Ed.), Encyclopedia of lifestyle medicine and health (pp. 2818-2829). Thousand Oaks, CA: SAGE.

11. Leeb, R. T., Lewis, T., \& Zolotor, A. J. (2011). A review of the physical and mental health consequences of child abuse and neglect and implications for practice. American Journal of Lifestyle Medicine, 5(5), 454-468.

12. Gilbert, L. K., Breiding, M. J., Merrick, M. T., Thompson, W. W., Ford, D. C., Dhingra, S. S., \& Parks, S. E. (2015). Childhood adversity and adult chronic disease. An update from ten states and the District of Columbia. American Journal of Preventive Medicine, 48(3), 345-349.

13. Fang, X., Brown, D. S., Florence, C. S., \& Mercy, J. A. (2012). The economic burden of child maltreatment in the United States and implications for prevention. Child Abuse \& Neglect, 36, 156-165.

14. Cicchetti, D., \& Toth, S. L. (2005). Child maltreatment. Annual Review of Clinical Psychology, 1, 409-438.

15. Petersen, A. C., Joseph, J., \& Feit, M. (Eds.). (2013). New directions in child abuse and neglect research. Washington, DC: The National Academies Press. Retrieved from http://www.nap.edu/read/ 18331/chapter/1.

16. Fixsen, D. L., Naoom, S. F., Blase, K. A., Friedman, R. M., \& Wallace, F. (2005). Implementation research: A synthesis of the literature. Tampa, FL: University of South Florida, Louis de la Parte Florida Mental Health Institute, National Implementation Research Network. (FMHI Publication No. 231).

17. Richmond-Crum, M., Joyner, C., Fogerty, S., Ellis, M. L., \& Saul, J. (2013). Applying a public health approach: The role of state health departments in preventing maltreatment and fatalities of children. Child Welfare, 92(2), 99-117.

18. Wilkins, N., Tsao, B., Hertz, M., Davis, R., \& Klevens, J. (2014). Connecting the dots: An overview of the links among multiple forms of violence. Atlanta, GA: National Center for Injury Prevention and Control, Centers for Disease Control and Prevention Oakland, CA: Prevention Institute. 
19. Finkelhor, D., Ormrod, R. K., \& Turner, H. A. (2009). Lifetime assessment of poly-victimization in a national sample of children and youth. Child Abuse and Neglect, 33, 403-411.

20. Hahm, H. C., Lee, Y., Ozonoff, A., \& Van Wert, M. J. (2010). The impact of multiple types of child maltreatment on subsequent risk behaviors among women during the transition from adolescence to young adulthood. Journal of Youth and Adolescence, $39,528-540$.

21. World Health Organization. (2010). Violence prevention: The evidence. Geneva, Switzerland: Author. Retrieved from http:// www.who.int/violence_injury_prevention/violence/4th_milestones_meeting/evidence_briefings_all.pdf.

22. Hamby, S., \& Grych, J. (2013). The web of violence: Exploring connections among different forms of interpersonal violence and abuse. In R. J. Johnson (Series Ed.), SpringerBriefs in Sociology (pp. 1-106). New York: Springer.

23. Caldera, D., Burrell, L., Rodriguez, K., Crowne, S. S., Rohde, C., \& Duggan, A. (2007). Impact of a statewide home visiting program on parenting and on child health and development. Child Abuse \& Neglect, 31(8), 829-852.

24. Olds, D. L., Eckenrode, J., Henderson, C. R., Kitzman, H., Powers, J., Cole, R., Sidora, K., Morris, P., Pettitt, L. M., \& Luckey, D. (1997). Long-term effects of home visitation on maternal life course and child abuse and neglect: Fifteen-year follow-up of a randomized trial. Journal of the American Medical Association, 278(8), 637-643.

25. Olds, D. L., Kitzman, H. L., Cole, R. E., Hanks, C. A., Arcoleo, K. J., Anson, E. A., Luckey, D. W., Knudtson, M. D., Henderson, Jr., C. R., Bondy, J., \& Stevenson, A. J. (2010). Enduring effects of prenatal and infancy home visiting by nurses on maternal life course and government spending: Follow-up of a randomized trial among children at age 12 years. Archives of Pediatrics \& Adolescent Medicine, 164(5), 419-424.

26. Mikton, C., \& Butchart, A. (2009). Child maltreatment prevention: A systematic review of reviews. Bulletin of the World Health Organization, 87(5), 353-361.

27. Chaffin, M., Silovsky, J. F., Funderburk, B., Valle, L. A., Brestan, E. V., Balachova, T., Jackson, S., Lensgraf, J., \& Bonner, B. L. (2004). Parent-Child Interaction Therapy with physically abusive parents: Efficacy for reducing future abuse reports. Journal of Consulting and Clinical Psychology, 72(3), 500-510.

28. Chaffin, M., Funderburk, B., Bard, D., Valle, L. A., \& Gurwitch, R. (2011). A combined motivation and Parent-Child Interaction Therapy package reduces child welfare recidivism in a randomized dismantling field trial. Journal of Consulting and Clinical Psychology, 79, 84-95.

29. Piquero, A. R., Farrington, D. P., Welsh, B. C., Tremblay, R., \& Jennings, W. G. (2008). Effects of early family/parenting programs on antisocial behavior and delinquency. Campbell Systematic Reviews, 1, 1-122.

30. Olds, D. L., Henderson, Jr., C. R., Cole, R., Eckenrode, J., Kitzman, H., Luckey, D., Pettitt, L., Sidora, K., Morris, P., \& Powers, J. (1998). Long-term effects of Nurse Home Visitation on children's criminal and antisocial behavior: 15-year follow-up of a randomized controlled trial. Journal of the American Medical Association, 280(14), 1238-1244.

31. Garces, E., Thomas, D., \& Currie, J. (2002). Longer term effects of Head Start. American Economic Review, 92(4), 999-1012.

32. Reynolds, A. J., Temple, J. A., Robertson, D. L., \& Mann, E. A. (2001). Long-term effects of an early childhood intervention on educational achievement and juvenile arrest: A 15-year follow-up of low-income children in public schools. Journal of the American Medical Association, 285(18), 2339-2346.

33. Reynolds, A. J., \& Ou, S. (2011). Paths of effects from preschool to adult well-being: A confirmatory analysis of the ChildParent Center program. Child Development, 82, 555-582.

34. Frieden, T. R. (2010). A framework for public health action: The health impact pyramid. American Journal of Public Health, 100, 590-595.

35. Cooper, K., \& Stewart, K. (2013). Does money affect children's outcomes? A systematic review. York, UK: Joseph Rowntree Foundation. Retrieved from http://www.jrf.org.uk/publications/does-money-affect-childrens-outcomes.

36. Shonkoff, J., Garner, A., \& Committee on Psychosocial Aspects of Child and Family Health, Committee on Early Childhood, Adoption, and Dependent Care, and Section on Developmental and Behavioral Pediatrics. (2012). The lifelong effects of early childhood adversity and toxic stress. Pediatrics, 129(1), e232-e246.

37. Stith, S. M., Liu, T., Davies, L. C., Boykin, E. L., Alder, M. C., Harris, J. M., Som, A., McPherson, M., \& Dees, J. E. M. E. G. (2009). Risk factors in child maltreatment: A meta-analytic review of the literature. Aggression and Violent Behavior, 14, 13-29. 
38. Center on Budget and Policy Priorities. (2015). Policy basics: The Earned Income Tax Credit. Retrieved from http://www.cbpp. org/research/federal-tax/policy-basics-the-earned-income-tax-credit.

39. United States Department of Agriculture (USDA). (2013). State options report, Supplemental Nutrition Assistance Program. Retrieved from http://www.fns.usda.gov/sites/default/files/snap/11-State_Options.pdf

40. Tiehen, L., Jolliffe, D., \& Gunderson, C. (2012). Alleviating poverty in the United States: The critical role of SNAP benefits. Washington, DC: U.S. Department of Agriculture, Economic Research Service.

41. Gibson-Davis, C., \& Foster, E. M. (2006). A cautionary tale: Using propensity scores to estimate the effect of Food Stamps on food insecurity. Social Service Review, 80, 93-126.

42. United States Department of Housing and Urban Development. (2016). Community development block grant program (CDBG) and section 8 housing voucher program. Washington, DC. More information is available at www.hud.gov.

43. Forry, N. D. (2009). The impact of child care subsidies on low-income single parents: An examination of child care expenditures and family finances. Journal of Family and Economic Issues, 30, 43-54.

44. National Women's Law Center. (2015). Child care. Helping parents in low-wage jobs access affordable child care: Opportunities under the reauthorized child care and development block grant. Retrieved from http://nwlc.org/wp-content/uploads/2015/08/ ccdbg_reauthorization_low-wage_workers_issue_brief_.pdf

45. Cancian, M., Yang, M., \& Slack, K. S. (2013). The effect of additional child support income on the risk of child maltreatment. Social Service Review, 87(3), 417-437.

46. Meyer, D. R., \& Cancian, M. (Eds.). (2001). W-2 child support demonstration evaluation, phase 1, final report, volume 2: The wellbeing of W-2 families. Retrieved from http://www.irp.wisc.edu/research/childsup/csde/csdesummary.htm\#list.

47. Cancian, M., \& Meyer, D. R. (2014). Testing the economic independence hypothesis: The effect of an exogenous increase in child support on subsequent marriage and cohabitation. Demography, 51, 857-880.

48. Radhakrishna, A., Bou-Saada, I. E., Hunter, W. M., Catellier, D. J., \& Kotch, J. B. (2001). Are father surrogates a risk factor for child maltreatment? Child Maltreatment, 6, 281-289.

49. Levitie, J., \& Koulish, J. (2008). State earned income tax credits: 2008 legislative update. Center on Budget and Policy Priorities. Retrieved from http://www.cbpp.org/cms/?fa=view\&id=462

50. Waldfogel, J. (2004). Welfare reform and the child welfare system. Children and Youth Services Review, 26, 919-929.

51. Arno, P. S., Sohler, N., Viola, D., \& Schechter, C. (2009). Bringing health and social policy together: The case of the Earned Income Tax Credit. Journal of Public Health Policy, 30, 198-207.

52. Dahl, G., \& Lochner, L. (2012). The impact of family income on child achievement. Evidence from the Earned Income Tax Credit. American Economic Review, 102(5), 1927-1956. http://dx.doi.org/10.1257/aer.102.5.1927

53. Marr, C., Charite, J., \& Huang, C. C. (2013). Earned Income Tax Credit promotes work, encourages children's success at school, research finds. Center on Budget and Policy Priorities. Retrieved from www.cbpp.org/files/6-26-12tax.pdf

54. Evans, W. N., \& Garthwaite, C. L. (2010). Giving mom a break: The impact of higher EITC payments on maternal health. NBER Working Paper No. 16296.

55. Pressman, S. (2011). Policies to reduce child poverty: Child allowances versus tax exemptions for children. Journal of Economic Issues, 45, 323-332.

56. Milligan, K., \& Stabile, M. (2011). Do child tax benefits affect the well-being of children? Evidence from Canadian child benefit expansions. American Economic Journal: Economic Policy, 3, 175-205.

57. Yang, M. (2015). The effect of material hardship on child protective service involvement. Child Abuse \& Neglect, 41, 113-125.

58. Lee, B. J., \& Mackey-Bilaver, L. (2007). Effects of WIC and Food Stamp program participation on child outcomes. Children and Youth Services Review, 29, 501-517.

59. United States Preventive Services Task Force (USPSTF), Guide to Community Preventive Services. (2001). Housing programs and policies: Tenant-based rental assistance programs. Retrieved from www.thecommunityguide.org/healthequity/housing/ tenantrental.html. 
60. Ludwig, J. (2012). The long-term results from the Moving to Opportunity residential mobility demonstration. Cityscape, 14(2), 1-28.

61. Ludwig, J., Duncan, G., Gennetian, L. A., Katz, L. F., Kessler, R. C., Kling, J. R., \& Sanbonmatsu, L. (2012). Neighborhood effects on the long term well-being of low-income adults. Science, 337(6101), 1505-1510.

62. Sanbonmatsu, L., Marvakov, J., Potter, N. A., Yang, F., Adam, E., Congdon, W. J., Duncan, G. J., Gennetian, L. A., Katz, L. F., Kling, J. R., Kessler, R. C., Lindau, S. T., Ludwig, J., \& McDade, T. W. (2012). The long term effects of Moving to Opportunity on adult health and economic self-sufficiency. Cityscape: A Journal of Policy Development and Research, 14, 109-135.

63. Chetty, R., Hendren, N., \& Katz, L. F. (in press). The effects of exposure to better neighborhoods on children: New evidence from the Moving to Opportunity experiment. American Economic Review.

64. Wood, M., Mills, G., Gubits, D., Orr, L., Long, D., Feins, J., Kaul, B., \& Jones, A. (2006). Effects of housing vouchers on welfare families. U.S. Department of Housing and Urban Development, Office of Policy Development and Research. Retrieved from http://www.huduser.gov/portal/publications/commdevl/hsgvouchers.html

65. Cowal, K., Shinn, M., Weitzman, B. C., Stojanovic, D., \& Labay, L. (2002). Mother-child separations among homeless and housed families receiving public assistance in New York City. American Journal of Community Psychology, 30, 711-730.

66. Michalopoulos, C., Lundquist, E., \& Castells, N. (2010). The effects of child care subsidies for moderate-income families in Cook County, Illinois. New York, New York: MDRC.

67. Schnitzer, P. G., \& Ewigman, B. G. (2005). Child deaths resulting from inflicted injuries: Household risk factors and perpetrator characteristics. Pediatrics, 116(5), e687-e693.

68. Klevens, J., Barnett, S. B., Florence, C., \& Moore, D. (2015). Exploring policies to reduce child physical abuse and neglect. Child Abuse \& Neglect, 40, 1-11.

69. Klein, S. (2011). The availability of neighborhood early care and education resources and the maltreatment of young children. Child Maltreatment, 16, 300-311.

70. Morrissey, T. W., \& Warner, M. E. (2007). Why early care and education deserves as much attention, or more, than prekindergarten alone. Applied Development Science, 11(2), 47-70.

71. Gordon, R. A., Usdansky, M. L., Wang, X., \& Guzman, A. (2011). Child care and mothers' mental health: Is high-quality care associated with fewer depressive symptoms? Family Relations, 60, 446-460.

72. Forget, E. L. (2011). The town with no poverty: The health effects of a Canadian guaranteed annual income field experiment. Canadian Public Policy, 37, 283-305.

73. Berger, L. M., Hill, J., \& Waldfogel, J. (2005). Maternity leave, early maternal employment and child health and development in the U.S. The Economic Journal, 115, F29-F27.

74. Strathearn, L., Mamun, A. A., Najmun, J. M., \& O'Callaghan, M. J. (2009). Does breastfeeding protect against substantiated abuse and neglect? A 15-year cohort study. Pediatrics, 123, 483-493.

75. Chatterji, P., \& Markowitz, S. (2005). Does the length of maternity leave affect maternal health? Southern Economic Journal, 72(1), 16-41.

76. Klevens, J., Luo, F., Xu, L., \& Latzman, N. E. (2016). Paid family leave's impact on hospital admissions for pediatric abusive head trauma. Injury Prevention. doi:10.1136/injuryprev-2015-041702 [e-pub ahead of print]

77. Aumann, K., \& Galinsky, E. (2009). The state of health in the American workforce: Does having an effective workplace matter? Retrieved from http://familiesandwork.org/downloads/Stateof HealthinAmericanWorkforce.pdf

78. Morsy, L., \& Rothstein, R. (2015). Parents' non-standard work schedules make adequate childrearing difficult: Reforming labor market practices can improve children's cognitive and behavioral outcomes. Economic Policy Institute, Issue Brief \#400. Retrieved from http://www.epi.org/files/ pdf/88777.pdf.

79. Han, W. (2005). Maternal nonstandard work schedules and child cognitive outcomes. Child Development, 76(1), 137-154.

80. Joshi, P., \& Bogen, K. (2007). Nonstandard schedules and young children's behavioral outcomes among working low-income families. Journal of Marriage and Family, 69, 139-156. 
81. Economic Policy Institute. (2015). Irregular work scheduling and its consequences. EPI Briefing Paper \#394. Retrieved from http://www.epi.org/files/pdf/82524.pdf.

82. Paluck, E. L., \& Ball, L. (2010). Social norms marketing aimed at gender based violence: A literature review and critical assessment. Retrieved from http://static1.squarespace.com/static/ 5186d08fe4b065e39b45b91e/t/52d1f24ce4b07fea75 9e4446/1389490764065/Paluck+Ball+IRC+Social+Norms+Marketing+Long.pdf

83. Lakoff, G. (2008). The political mind. New York: Penguin.

84. Davey, L. (2014). Understanding message framing for effective policy communications. Children's Safety Network South to Southwest Webinar. Retrieved from http://www.childrens safetynetwork.org/webinar/south-southwest-webinar-s2swunderstanding-message-framing-effective-policy-communications.

85. Global Initiative to End All Corporal Punishment of Children. (2015). Country report for USA. Retrieved from http://www. endcorporalpunishment.org/progress/country-reports/usa.html.

86. Grier, S., \& Bryant, C. A. (2005). Social marketing in public health. Annual Review of Public Health, 26, 319-339.

87. Horsfald, B., Bromsfield, L., \& McDonald, M. (2010). Are social marketing campaigns effective in preventing child abuse and neglect? National Child Protection Clearinghouse, 32. Retrieved from https://aifs.gov.au/cfca/publications/are-socialmarketing-campaigns-effective-preventing-child.

88. Stannard, S., Hall, S., \& Young, J. (1998). Social marketing as a tool to stop child abuse. Social Marketing Quarterly, Summer, 6468.

89. Henley, N., Donovan, R. J., \& Morehead, H. (1998). Appealing to positive motivations and emotions in social marketing: Example of a positive parenting campaign. Social Marketing Quarterly, Summer, 49-53.

90. Osterman, K., Bjorkqvist, K., \& Wahlbeck, K. (2014). Twenty eight years after the complete ban on physical punishment of children in Finland: Trends and psychosocial concomitants. Aggressive Behavior, 40, 568-581.

91. Roberts, J. V. (2000). Changing public attitudes towards corporal punishment: The effects of statutory reform in Sweden. Child Abuse \& Neglect, 24(8), 1027-1035.

92. Sariola, H. (2012). Attitudes to disciplinary violence. Finland: Central Union for Child Welfare.

93. Bussman, K., Erthal, C., \& Schroth, A. (2011). Effects of banning corporal punishment in Europe - A five nation comparison. In J. E. Durrant \& A. B. Smith (Eds), Global pathways to abolishing physical punishment (pp. 299-322). New York: Routledge.

94. Zolotor, A. J., \& Puzia, M. E. (2010). Bans against corporal punishment: A systematic review of the laws, changes in attitudes and behaviours. Child Abuse Review, 19, 229-247.

95. Cash, S. J., \& Wilke, D. J. (2003). An ecological model of maternal substance abuse and child neglect: Issues, analyses, and recommendations. American Journal of Orthopsychiatry, 73, 392-404.

96. Reynolds, A. J., \& Robertson, D. L. (2003). School-based early intervention and later child maltreatment in the Chicago Longitudinal Study. Child Development, 74(1), 3-26.

97. Mersky, J. P., Topitzes, J. D., \& Reynolds, S. W. (2011). Maltreatment prevention through early childhood intervention: A confirmatory evaluation of the Chicago Child-Parent Center preschool program. Children \& Youth Services Review, 33, 14541463.

98. Chicago Public Schools. (2014). Child Parent Center. Retrieved from http://cps.edu/Schools/Early Childhood/Pages/ Childparentcenter.aspx.

99. National Association for the Education of Young Children. (2015). NAEYC early childhood program standards and accreditation criteria: Revised guidance for assessment - Effective October 1, 2015. Retrieved from http://www.naeyc.org/academy/primary/ viewstandards.

100. Reynolds, A. J., Temple, J. A., Ou, S. R., Robertson, D. L., Mersky, J. P., Topitzes, J. W., \& Niles, M. D. (2007). Effects of a schoolbased, early childhood intervention on adult health and well-being: A 19-year follow-up of low-income families. Archives of Pediatrics and Adolescent Medicine, 161(8), 730-739.

101. Reynolds, A. J., Temple, J. A., White, B. A. B., Ou, S., \& Robertson, D. L. (2011). Age-26 cost-benefit analysis of the Child-Parent Early Education Program. Child Development, 82, 379-404. 
102. Love, J. M., Kisker, E. E., Ross, C., Constantine, J., Boller, K., Brooks-Gunn, J., Chazan-Cohen, R., Tarullo, L. B., Brady-Smith, C., Fuligni, A. S., Schochet, P. Z., Paulsell, D., \& Vogel, C. (2005). The effectiveness of Early Head Start for 3-year-old children and their parents: Lessons for policy and programs. Developmental Psychology, 41, 885-901.

103. Green, B. L., Ayoub, C., Bartlett, J. D., Von Ende, A., Furrer, C., Chazan-Cohen, R., Vallotton, C., \& Klevens, J. (2014). The effect of Early Head Start on child welfare system involvement: A first look at longitudinal child maltreatment outcomes. Children and Youth Services Review, 42, 127-135.

104. Pluess, M., \& Belsky, J. (2009). Differential susceptibility to rearing experience: The case of childcare. Journal of Child Psychology and Psychiatry, 50(4), 396-404.

105. Watamura, S. E., Phillips, D. A., Morrissey, T. W., McCartney, K., \& Bub, K. (2011). Double jeopardy: Poorer social-emotional outcomes for children in the NICHD SECCYD experiencing home and child-care environments that confer risk. Child Development, 82(1), 48-65.

106. National Scientific Council on the Developing Child. (2004). Young children develop in an environment of relationships: Working paper no. 1. Retrieved from http://developingchild.harvard.edu/resources/reports_and_working_papers/working_ papers/wp1\%.

107. Slack, K. S., Holl, J. L., McDaniel, M., Yoo, J., \& Bolger, K. (2004). Understanding the risks of child neglect: An exploration of poverty and parenting characteristics. Child Maltreatment, 9, 395-408.

108. Yeung, W. J., Linver, M. R., \& Brooks-Gunn, J. (2002). How money matters for young children's development: Parental investment and family processes. Child Development, 73, 1861-1879.

109. Kaminski, J. W., Valle, L. A., Filene, J. H., \& Boyle, C. L. (2008). A meta-analytic review of components associated with parent training program effectiveness. Journal of Abnormal Child Psychology, 36, 567-589.

110. Lundahl, B., Risser, H. J., \& Lovejoy, M. C. (2006). A meta-analysis of parent training: Moderators and follow-up effects. Clinical Psychology Review, 26, 86-104.

111. Taylor, T. K., \& Biglan, A. (1998). Behavioral family interventions for improving child-rearing: A review of the literature for clinicians and policy-makers. Clinical Child and Family Psychology Review, 1(1), 41-60.

112. Whitaker, D. J., Lutzker, J. R., \& Shelley, G. A. (2005). Child maltreatment prevention priorities at the Centers for Disease Control and Prevention. Child Maltreatment, 10(3), 245-259.

113. Nurse Family Partnership. (2011). Evidence-based public policy. Retrieved from http://www.nurse familypartnership.org/ public-policy.

114. Dodge, K. A., Goodman, W. B., Murphy, R., O'Donnell, K. J., \& Sato, J. M. (2013). Toward population impact from home visiting. Zero to Three, 33(3), 17-23.

115. Fortson, B. L., Martin, J. B., \& Lokey, C. N. (2015). Prevention of child abuse and neglect. In P. T. Clements \& A. Burgess (Eds.), Nursing approach to the evaluation of child maltreatment ( $2^{\text {nd }}$ edition). Saint Louis, MO: STM Learning.

116. Knox, M. S., Burkhart, K., \& Hunter, K. E. (2011). ACT Against Violence Parents Raising Safe Kids program: Effects on maltreatment-related parenting behaviors and beliefs. Journal of Family Issues, 32, 55-74.

117. Portwood, S. G., Lambert, R. G., Abrams, L. P., \& Nelson, E. B. (2011). An evaluation of the Adults and Children Together (ACT) Against Violence Parents Raising Safe Kids program. Journal of Primary Prevention, 32, 147-160.

118. Gonzalez, A., \& MacMillan, H. L. (2008). Preventing child maltreatment: An evidence-based update. Journal of Postgraduate Medicine, 54(4), 280-286.

119. Sweet, M. A., \& Appelbaum, M. I. (2004). Is home visiting an effective strategy? A meta-analytic review of home visiting programs for families with young children. Child Development, 75(5), 1435-1456.

120. Avellar, S., Paulsell, D., Sama-Miller, E., Del Grosso, P., Akers, L., \& Kleinman, R. (2015). Home visiting evidence of effectiveness review: Executive summary. Washington, DC: Office of Planning, Research and Evaluation, Administration for Children and Families, U.S. Department of Health and Human Services. Retrieved from http://homvee.acf.hhs.gov/HomVEE_Executive_ Summary_2015.pdf. 
121. Olds, D. L., Kitzman, H., Hanks, C., Cole, R., Anson, E., Sidora-Arcoleo, K., Luckey, D. W., Henderson, Jr., C. R., Holmberg, J., Tutt, R. A., Stevenson, A. J., \& Bondy, J. (2007). Effects of nurse home visiting on maternal and child functioning: Age-9 follow-up of a randomized trial. Pediatrics, 120, e832-e845.

122. Mejdoubi, J., van den Heijkant, S. C. C. M., van Leerdam, F. J. M., Heymans, M. W., Crijnen, A., \& Hirasing, R. A. (2015). The effect of VoorZorg, the Dutch Nurse-Family Partnership, on child maltreatment and development: A randomized controlled trial. PLoS One, 10(4), e0120182.

123. Dodge, K. A., Goodman, W. B., Murphy, R. A., O'Donnell, K., Sato, J., \& Guptill, S. (2014). Implementation and randomized controlled trial evaluation of universal postnatal nurse home visiting. American Journal of Public Health, 104(S1), S136-S143.

124. Dodge, K. A., Goodman, W. B., Murphy, R. A., O'Donnell, K., \& Sato, J. (2013). Randomized controlled trial of universal postnatal nurse home visiting: Impact on emergency care. Pediatrics, 132, S140-S146.

125. Blueprints for Healthy Youth Development. (2015). Incredible Years - Parent. Retrieved from http://www.blueprintsprograms. com/factSheet.php?pid=7719a1c782a1ba91c031a682a0a2f8658209adbf.

126. Webster-Stratton, C., Reid, M. J., \& Hammond, M. (2001). Preventing conduct problems, promoting social competence: A parent and teacher training partnership in Head Start. Journal of Clinical Child Psychology, 30, 283-302.

127. The California Evidence-Based Clearinghouse for Child Welfare. (2015). SafeCare. Retrieved from http://www.cebc4cw.org/ program/safecare/detailed.

128. Carta, J. J., Lefever, J. B., Bigelow, K., Borkowski, J., \& Warren, S. F. (2013). Randomized trial of a cellular phone-enhanced home visitation parenting intervention. Pediatrics, 132, S167-S173.

129. Felitti, V. J., Anda, R. F., Nordenberg, D., Williamson, D. F., Spitz, A. M., Edwards, V., Koss, M. P., \& Marks, J. S. (1998). Relationship of childhood abuse and household dysfunction to many of the leading causes of death in adults: The Adverse Childhood Experiences (ACE) study. American Journal of Preventive Medicine, 14(4), 245-258.

130. Lanier, P., Jonson-Reid, M., Stahlschmidt, M. J., Drake, B., \& Constantino, J. (2010). Child maltreatment and pediatric health outcomes: A longitudinal study of low-income children. Journal of Pediatric Psychology, 35, 511-522.

131. Finkelhor, D., Ormrod, R. K., \& Turner, H. A. (2007). Poly-victimization: A neglected component in child victimization. Child Abuse \& Neglect, 31, 7-26.

132. Gilbert, R., Widom, C. S., Browne, K., Fergusson, D., Webb, E., \& Janson, S. (2009). Burden and consequences of child maltreatment in high-income countries. Lancet, 373, 68-81.

133. Holt, S., Buckley, H., \& Whelan, S. (2008). The impact of exposure to domestic violence on children and young people: A review of the literature. Child Abuse \& Neglect, 32, 797-810.

134. Renner, L., \& Slack, K. (2006). Intimate partner violence and child maltreatment: Understanding intra-and intergenerational connections. Child Abuse \& Neglect, 30, 599-617.

135. Widom, C. S., Czaja, S., \& Dutton, M. A. (2014). Child abuse and neglect and intimate partner violence victimization and perpetration: A prospective investigation. Child Abuse \& Neglect, 38, 650-663.

136. Silverman, W. K., Ortiz, C. O., Viswesvaran, C., Burns, B. J., Kolko, D. J., Putnam, F. W., \& Amaya-Jackson, L. (2008). Evidencebased psychosocial treatments for children and adolescents exposed to traumatic events. Journal of Clinical Child \& Adolescent Psychology, 37, 156-183.

137. Dubowitz, H., Feigelman, S., Lane, W., \& Kim, J. (2009). Pediatric primary care to help prevent child maltreatment: The Safe Environment for Every Kid (SEEK) model. Pediatrics, 123(3), 858-864.

138. Dubowitz, H., Lane, W. G., Semiatin, J. N., \& Magder, L. S. (2012). The SEEK model of pediatric primary care: Can child maltreatment be prevented in a low-risk population? Academic Pediatrics, 12(4), 259-268.

139. Hurlburt, M. S., Nguyen, K., Reid, J., Webster-Stratton, C., \& Zhang, J. (2013). Efficacy of the Incredible Years group parent program with families in Head Start who self-reported a history of child maltreatment. Child Abuse and Neglect, 37, 531-543.

140. Letarte, M. J., Normandeau, S., \& Allard, J. (2010). Effectiveness of a parent training program "Incredible Years" in a child protection service. Child Abuse \& Neglect, 34, 253-261. 
141. Silovsky, J. F., Bard, D., Chaffin, M., Hecht, D., Burris, L., Owora, A., \& Lutzker, J. (2011). Prevention of child maltreatment in high-risk rural families: A randomized clinical trial with child welfare outcomes. Children and Youth Services Review, 33, 14351444.

142. Gershater-Molko, R. M., Lutzker, J. R., \&Wesch, D. (2002). Using recidivism data to evaluate Project SafeCare: Teaching bonding, safety, and health care skills to parents. Child Maltreatment, 7, 277-285.

143. Webster-Stratton, C., \& Reid, M. (2010). Adapting The Incredible Years: An evidence-based parenting programme for families involved in the child welfare system. Journal of Children's Services, 5(1), 25-42.

144. Linares, L. O., Montalto, D., Li, M., \& Oza, S. V. (2006). A promising parent intervention in foster care. Journal of Consulting and Clinical Psychology, 74, 32-41.

145. Cary, C. E., \& McMillen, J. C. (2012). The data behind the dissemination: A systematic review of trauma-focused cognitive behavioral therapy for use with children and youth. Children and Youth Services Review, 34, 748-757.

146. Mannarino, A. P., Cohen, J. A., Deblinger, E., Runyon, M. K., \& Steer, R. A. (2012). Trauma-Focused Cognitive-Behavioral Therapy for sustained impact of treatment 6 and 12 months later. Child Maltreatment, 17(3), 231-241.

147. Carpentier, M., Silovsky, J. F., \& Chaffin, M. (2006). Randomized trial of treatment for children with sexual behavior problems: Ten year follow-up. Journal of Consulting and Clinical Psychology, 74(3), 482-488.

148. Cohen, J. A., \& Mannarino, A. P. (1997). A treatment study for sexually abused preschool children: Outcome during a one-year follow-up. Journal of the American Academy of Child and Adolescent Psychiatry, 36, 1228-1235.

149. Friedrich, W. N., Luecke, W., Beilke, R. L., \& Place, V. (1992). Psychotherapy outcome with sexually abused boys: An agency study. Journal of Interpersonal Violence, 7, 396-409.

150. Henggeler, S. W., Cunningham, P. B., Schoenwald, S. K., Borduin, C. M., \& Rowland, M. D. (2009). Multisystemic Therapy for antisocial behavior in children and adolescents ( $2^{\text {nd }}$ ed.). New York: Guilford.

151. Brunk, M., Henggeler, S. W., \& Whelan, J. P. (1987). A comparison of Multisystemic Therapy and parent training in the brief treatment of child abuse and neglect. Journal of Consulting and Clinical Psychology, 55, 311-318.

152. Swenson, C. C., Schaeffer, C., Henggeler, S. W., Faldowski, R., \& Mayhew, A. M. (2010). Multisystemic Therapy for child abuse and neglect: A randomized effectiveness trial. Journal of Family Psychology, 24, 497-507.

153. Schaeffer, C. M., Swenson, C. C., Tuerk, E. H., \& Henggeler, S. W. (2013). Comprehensive treatment for co-occurring child maltreatment and parental substance abuse: Outcomes from a 24-month pilot study of the MST-Building Stronger Families program. Child Abuse and Neglect, 37(8), 596-607.

154. van der Stouwe, T., Asscher, J. J., Stams, G. J. J. M., Deković, M., \& van der Laan, P. H. (2014). The effectiveness of Multisystemic Therapy (MST): A meta-analysis. Clinical Psychology Review, 34(6), 468-481.

155. Palusci, V., \& Covington, T. (2014). Child maltreatment deaths in the U. S. National Child Death Review Case Reporting System. Child Abuse \& Neglect, 38, 25-36. 


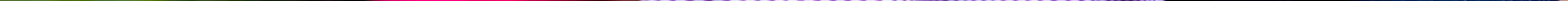




\section{Appendix: Summary of Strategies and Approaches to Prevent Child Abuse and Neglect}

\begin{tabular}{|c|c|c|c|c|c|}
\hline Strategy & $\begin{array}{l}\text { Approach/Program, } \\
\text { Practice or Policy }\end{array}$ & $\begin{array}{c}\text { CAN } \\
\text { Perpetration }\end{array}$ & $\begin{array}{c}\text { CAN } \\
\text { Victimization }\end{array}$ & $\begin{array}{l}\text { Risk Factor } \\
\text { for CAN }\end{array}$ & Lead Sectors ${ }^{1}$ \\
\hline \multirow{10}{*}{$\begin{array}{l}\text { Strengthen } \\
\text { economic supports } \\
\text { to families }\end{array}$} & \multicolumn{4}{|c|}{ Strengthening household financial security } & \multirow{6}{*}{$\begin{array}{l}\text { Business/Labor } \\
\text { Government } \\
\text { (local, state, } \\
\text { Federal) }\end{array}$} \\
\hline & Child support payments & & $\checkmark$ & $\checkmark$ & \\
\hline & Tax credits & & & $\checkmark$ & \\
\hline & $\begin{array}{l}\text { State nutrition assistance } \\
\text { programs }\end{array}$ & & $\checkmark$ & $\checkmark$ & \\
\hline & Assisted housing mobility & & & $\checkmark$ & \\
\hline & Subsidized child care & & $\checkmark$ & $\checkmark$ & \\
\hline & \multicolumn{4}{|l|}{ Family-friendly work policies } & \multirow{4}{*}{$\begin{array}{l}\text { Business/Labor } \\
\text { Government } \\
\text { (local, state, } \\
\text { Federal) }\end{array}$} \\
\hline & Livable wages & & & $\checkmark$ & \\
\hline & Paid leave & & $\checkmark$ & $\checkmark$ & \\
\hline & Flexible and consistent schedules & & & $\checkmark$ & \\
\hline \multirow{4}{*}{$\begin{array}{l}\text { Change social } \\
\text { norms to support } \\
\text { parents and } \\
\text { positive parenting }\end{array}$} & \multicolumn{4}{|c|}{ Public engagement and education campaigns } & \multirow{2}{*}{ Public Health } \\
\hline & Breaking the Cycle & & & $\checkmark$ & \\
\hline & \multicolumn{4}{|c|}{ Legislative approaches to reduce corporal punishment } & \multirow{2}{*}{$\begin{array}{l}\text { Government } \\
\text { (local, state, } \\
\text { Federal) }\end{array}$} \\
\hline & $\begin{array}{l}\text { Bans pertaining to home, school, } \\
\text { other settings }\end{array}$ & & & $\checkmark$ & \\
\hline \multirow{5}{*}{$\begin{array}{l}\text { Provide quality care } \\
\text { and education early } \\
\text { in life }\end{array}$} & \multicolumn{4}{|c|}{ Preschool enrichment with family engagement } & \multirow{3}{*}{$\begin{array}{l}\text { Social Services } \\
\text { Public Health }\end{array}$} \\
\hline & Child Parent Centers & & $\checkmark$ & $\checkmark$ & \\
\hline & Early Head Start & & $\checkmark$ & $\checkmark$ & \\
\hline & \multicolumn{4}{|c|}{ Improved quality of child care through licensing and accreditation } & \multirow{2}{*}{$\begin{array}{l}\text { Business/labor } \\
\text { Government } \\
\text { (local, state, } \\
\text { Federal) } \\
\end{array}$} \\
\hline & Licensing and accreditation & & & $\checkmark$ & \\
\hline
\end{tabular}

'This column refers to the lead sectors well positioned to bring leadership and resources to implementation efforts. For each strategy, there are many other sectors such as non-governmental organizations that are instrumental to prevention planning and implementing the specific programmatic activities.

${ }^{2}$ Program was designed to address the harms of abuse and neglect (e.g., PTSD, depression). 


\begin{tabular}{|c|c|c|c|c|c|}
\hline Strategy & $\begin{array}{l}\text { Approach/Program, } \\
\text { Practice or Policy }\end{array}$ & $\begin{array}{c}\text { CAN } \\
\text { Perpetration }\end{array}$ & $\begin{array}{c}\text { CAN } \\
\text { Victimization }\end{array}$ & $\begin{array}{l}\text { Risk Factor } \\
\text { for CAN }\end{array}$ & Lead Sectors $^{1}$ \\
\hline \multirow{7}{*}{$\begin{array}{l}\text { Enhance parenting } \\
\text { skills to promote } \\
\text { healthy child } \\
\text { development }\end{array}$} & \multicolumn{4}{|l|}{ Early childhood home visitation } & \multirow{3}{*}{$\begin{array}{l}\text { Public Health } \\
\text { Health Care }\end{array}$} \\
\hline & Nurse Family Partnership & $\checkmark$ & & $\checkmark$ & \\
\hline & Durham Connects & & & $\checkmark$ & \\
\hline & \multicolumn{4}{|c|}{ Parenting skill and family relationship approaches } & \multirow{4}{*}{$\begin{array}{l}\text { Public Health } \\
\text { Social Services }\end{array}$} \\
\hline & $\begin{array}{l}\text { Adults and Children Together } \\
\text { Against Violence: Parents Raising } \\
\text { Safe Kids (ACT) }\end{array}$ & $\checkmark$ & & $\checkmark$ & \\
\hline & Incredible Years & & & $\checkmark$ & \\
\hline & Safe Care & & & $\checkmark$ & \\
\hline \multirow{11}{*}{$\begin{array}{l}\text { Intervene to lessen } \\
\text { harms and prevent } \\
\text { future risk }\end{array}$} & \multicolumn{4}{|l|}{ Enhanced primary care } & \multirow{2}{*}{$\begin{array}{l}\text { Public Health } \\
\text { Health Care }\end{array}$} \\
\hline & $\begin{array}{l}\text { Safe Environment for Every Kid } \\
\text { (SEEK) }\end{array}$ & $\checkmark$ & & $\checkmark$ & \\
\hline & \multicolumn{4}{|l|}{ Behavioral parent training programs } & \multirow{4}{*}{$\begin{array}{l}\text { Public Health } \\
\text { Social Services }\end{array}$} \\
\hline & $\begin{array}{l}\text { Parent-Child Interaction Therapy } \\
\text { (PCIT) }\end{array}$ & $\checkmark$ & & $\checkmark$ & \\
\hline & Safe Care & $\checkmark$ & & $\checkmark$ & \\
\hline & Incredible Years & & & $\checkmark$ & \\
\hline & \multicolumn{4}{|c|}{ Treatment to lessen harms of abuse and neglect exposure } & \multirow{2}{*}{$\begin{array}{l}\text { Health Care } \\
\text { Social Services } \\
\text { Justice }\end{array}$} \\
\hline & $\begin{array}{l}\text { Trauma-Focused Cognitive } \\
\text { Behavioral Therapy (TF-CBT) }\end{array}$ & $N / A^{2}$ & $\mathrm{~N} / \mathrm{A}^{2}$ & $\checkmark$ & \\
\hline & \multicolumn{4}{|c|}{ Treatment to prevent problem behavior and later involvement in violence } & \multirow{3}{*}{$\begin{array}{l}\text { Health Care } \\
\text { Social Services } \\
\text { Justice }\end{array}$} \\
\hline & $\begin{array}{l}\text { Children with Problematic Sexual } \\
\text { Behavior Cognitive-Behavioral } \\
\text { Treatment Program: School-age } \\
\text { Program }\end{array}$ & & & $\checkmark$ & \\
\hline & Multisystemic Therapy (MST) & $\checkmark$ & & $\checkmark$ & \\
\hline
\end{tabular}

'This column refers to the lead sectors well positioned to bring leadership and resources to implementation efforts. For each strategy, there are many other sectors such as non-governmental organizations that are instrumental to prevention planning and implementing the specific programmatic activities.

${ }^{2}$ Program was designed to address the harms of abuse and neglect (e.g., PTSD, depression). 




\section{For more information}

To learn more about youth violence prevention, call 1-800-CDC-INFO or visit CDC's violence prevention pages at www.cdc.gov/violenceprevention. 